\title{
Entre la heráldica y la emblemática: reorientación semántica de dos motivos animalísticos en blasones nobiliarios del casco histórico de Cáceres ${ }^{1}$
}

\author{
José Julio García Arranz \\ Universidad de Extremadura \\ jjturko@gmail.com
}

\begin{abstract}
RESUMEN: En los edificios, capillas y enterramientos del conjunto monumental de la ciudad de Cáceres se conserva un nutrido repertorio de escudos heráldicos cuyos testimonios más tempranos se remontan al siglo XIV. En algunos casos, los componentes figurados de esas armerías familiares se acompañan de sentencias inscritas que, de algún modo, complementan o incluso reorientan con nuevos contenidos semánticos el carácter informativo, conmemorativo o propagandístico de los escudos. En el presente artículo vamos a examinar dos de esos blasones, que presiden respectivamente las fachadas principales de las casas-palacio de los Espadero-Pizarro y de los Blázquez-Mayoralgo, en los que sendas inscripciones asociadas confieren un nuevo sentido «emblemático» a los correspondientes motivos zoomorfos del león y el águila que figuran en dichos dispositivos.
\end{abstract}

PALABRAS CLAVE: Cáceres; Blasón; Epigrafía heráldica; Casa Espadero-Pizarro; Palacio Mayoralgo.

\section{Between the Heraldic and the Emblematic: Semantic Reorientation of Two Animalistic Motifs in Noble Coats of Arms in the Historic Centre of Cáceres}

ABSTRACT: A large repertoire of heraldic coats of arms, the earliest dating from the $14^{\text {th }}$ century, is preserved in the buildings, chapels and tombs that make up the monuments of the city of Cáceres. In some cases, the figurative components of these family arms are accompanied by mottos that, in some way, complement or even reorient the informative, commemorative or propagandistic nature of the family escutcheon with new semantic content. In this article we will examine two of these escutcheons, which preside over the main façades of the Espadero-Pizarro and Blázquez-Mayoralgo palaces respectively, and in which both associated inscriptions confer a new «emblematic» meaning to the corresponding zoomorphic motifs of the lion and the eagle that appear on these devices.

KEYWORDS: Cáceres; Escutcheon; Heraldic Epigraphy; Espadero-Pizarro House; Mayoralgo Palace.

El conjunto histórico-monumental de Cáceres muestra en las portadas, muros, capillas y sepulcros de sus edificios un amplio y diversificado patrimonio de escudos nobiliarios pertenecientes a las principales familias y promotores que contribuyeron a sus empresas constructivas, tanto en el ámbito de lo civil como en el eclesiástico y militar². Por lo general, salvo requisito específico heráldico o devocional, o bien añadido de breve leyenda relativa a determinada actuación o reforma ${ }^{3}$, estos blasones no suelen acompañarse de elemento textual alguno asociado a su imaginario. Sin embargo, en algunas ocasiones nos encontramos con la presencia, en la proximidad de estas armerías, de una inscripción alusiva al escudo o a alguno de sus componentes a modo de recurso parlante que ayuda a aportar una dimensión significativa que complementa o incluso reorienta con nuevos contenidos la habitual dimensión informativa, conmemorativa o propagandística de aquellos dispositivos heráldicos. De este modo, las armas familiares se apartan momentáneamente de su función original, deslizándose, con el añadido de la letra, hacia el ámbito de las divisas o empresas personales, insignias de carácter más individualizado con

Cómo citar este artículo: GARCÍA ARRANZ, José Julio, «Entre la heráldica y la emblemática: reorientación semántica de dos motivos animalísticos en blasones nobiliarios del casco histórico de Cáceres", Boletín de Arte-UMA, n. ${ }^{\circ}$ 40, Departamento de Historia del Arte, Universidad de Málaga, 2019, pp. 43-60, ISSN: 0211-8483, e-ISSN: 2695-415X, DOI: http://dx.doi.org/10.24310/BoLArte.2019.v0i40.6383 
las que se trata de expresar un anhelo, un propósito o una reivindicación particular, y que alcanzaron su momento de mayor popularidad a fines de la Edad Media e inicios de los tiempos modernos.

En consonancia con este dato, parece que la incorporación de estos complementos epigráficos a determinadas partes de las portadas o fachadas de la arquitectura civil, bajo forma de sentencias que adquieren el formato de lemas o motes en evidente asociación -como así sucede en los casos que aquí vamos a analizar- a los correspondientes escudos heráldicos, es una práctica local que, a la vista de las muestras conservadas, se inicia a finales del s. XV y se perpetúa a lo largo de la siguiente centuria. Es interesante constatar cómo, de las citas de índole religiosa procedentes de versículos bíblicos, se pasa progresivamente a sentencias de carácter más humanista o de inspiración clásica que constituyen tempranos testimonios de los ecos renacientes que llegan de Italia cada vez con mayor intensidad. Como ejemplos reseñables del primer caso podemos mencionar el epígrafe de la casa fuerte gótica de los Sánchez Paredes -en la calle Puerta de Mérida-, reformada en el s. XVI, bajo cuyo blasón frontero figura la inscripción: NON HABEMUS HIC ClVITATEM MANENTEM SED FUTURAM INQUIRIMUS ${ }^{4}$, o el del palacio de Hernando de Ovando -en la plaza de Santa María-, donde, en el friso que discurre por encima de la puerta principal, se puede leer: AETERNA IUSTORUM MEMORIAE ${ }^{5}$; por su parte, a unos fundamentos culturales e ideológicos ya distintos responden los epígrafes de la fachada principal del palacio de la Isla -plaza de la Concepción-; allí, al amparo de sendas líneas molduradas de cornisa -la que se dispone como remate del balcón abierto sobre la portada manierista, y la más extensa que separa el primero de los pisos superiores, interrumpida esta por el mencionado balcón-, corren los correspondientes frisos con las sentencias: MOdERATA DURANT y NOBILIA ANIMUS NON ACTA PARENTUM 6 .

En el presente artículo vamos a abordar el análisis de dos de estos casos, en los que encontramos la mencionada asociación icónico-verbal que implica a sendos motivos zoomórficos tremendamente frecuentes, por lo demás, en el imaginario heráldico bajomedieval: el león y el águila. Ambos se disponen en los blasones que presiden las fachadas principales de edificios bien conocidos en dicho conjunto monumental cacereño: los palacios de Espadero-Pizarro y de Mayoralgo.

\section{El blasón de los Cáceres-De los Nidos en la Casa del Mono o palacio Espadero-Pizarro}

La casa-palacio de los Espadero-Pizarro -tal y como aparece identificada en la bibliografía precedente-, popularmente conocida en Cáceres como «Casa del Mono», es considerada, a pesar de sus modestas proporciones y la reciedumbre de sus materiales y líneas arquitectónicas, uno de los ejemplares más bellos de la arquitectura urbana bajomedieval de la ciudad (Lozano, 1980: 214) [1]. Situado en la Cuesta de Aldana, dentro del recinto intramuros cacereño, el inmueble presenta planta trapezoidal un tanto irregular en su forzado ajuste a los límites del solar en que se ubica, con las estancias organizadas en torno a un patio central. A causa del marcado declive del terreno que le sirve de asiento, especialmente visible en el frente de la fachada, lo abrupto del solar, con el afloramiento de roca natural en algunas de sus estancias, y las modificaciones y reformas que la casa ha ido experimentando a lo largo de su historia, nos encontramos ante un edificio de proporciones un tanto desiguales en su aspecto externo, donde sobresalen en altura los dos volúmenes de los ángulos del lado norte, arranques de sendas torres desmochadas a consecuencia de la política de castigo y humillación de las familias opositoras ejercida mediante edicto publicado en 1476 por Isabel la Católica. Los muros son de mampostería con sillares graníticos en las esquinas y recercado de vanos.

La portada principal se abre en arco de medio punto peraltado con grandes dovelas planas tan características de la arquitectura cacereña del momento. Sobre su eje central se sitúa un pequeño alfiz que, resaltado, sirve de antepecho a una ventana superior gótica con arco conopial al tiempo que cobija el escudo cuartelado sobre el que en seguida volveremos. La zona central del frente de la casa se remata con saliente cornisa moldurada, ornada con tres llamativas gárgolas figuradas. Diversas ventanas, pertenecientes a diferentes momentos y distribuidas desigualmente, animan sus paramentos; una de ellas conserva un interesante relieve inferior a modo de pretil, con una trama romboidal que cobija motivos florales tetralobulados.

A través de un profundo zaguán con bóvedas de arista de ladrillo visto tras la última restauración, se accede al patio interior con galerías de arcos escarzanos en dos de sus lados dispuestos sobre columnas de capiteles y bases facetadas. 


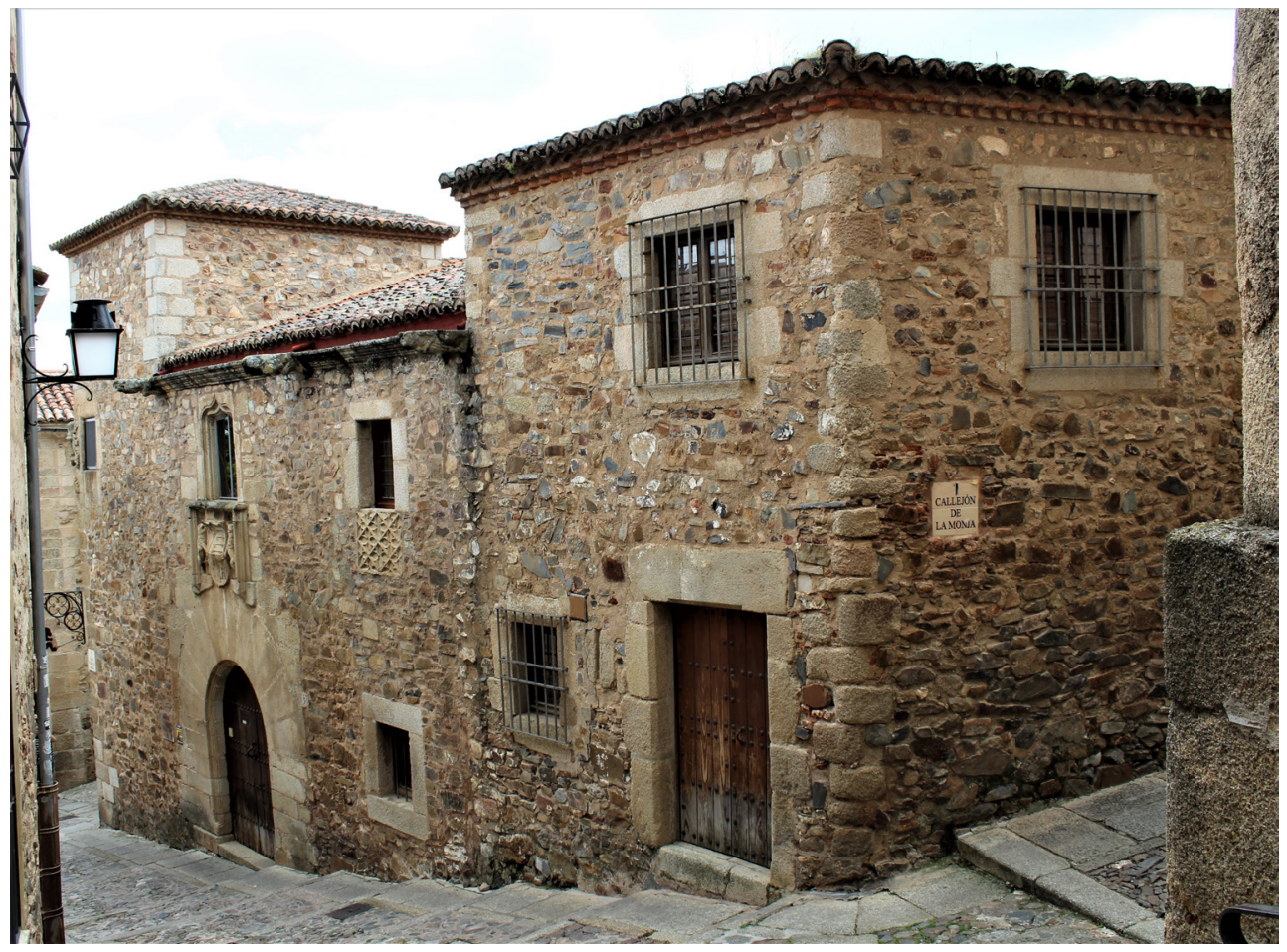

1. Casa-palacio de los Espadero-Pizarro o de Cáceres-De los Nidos, Cáceres. Vista general del frente de fachada

En el piso alto aparece una galería con antepecho y arcos también rebajados. Pero, sin duda, el elemento más llamativo de este espacio es la escalera de cantería de dos tramos de ida y vuelta, con barandas de granito, que se dispone en el lado norte; al final del primer tramo, en el muro de la escalera y arranque del barandal superior, hay una escultura en piedra que representa a un mono atado con una cadena y debajo una pequeña ventana cuadrada por la que se asoma un rostro humano con marcados rasgos étnicos ${ }^{7}$. Diversos detalles decorativos góticos perviven en varias portadas y antepechos de ventanas; las habitaciones se cubren con techumbre plana con viguerías de madera o bóvedas de aristas de ladrillo (Andrés y Pizarro, 2006: vol. I, pp. 215-217; Mogollón, 1995b).

A la vista de los elementos señalados, se viene considerando que muy probablemente se trate de una construcción de la época de los Reyes Católicos -finales del siglo XV-, con posibles reformas en el quinientos (Mélida, 1924: 53-54; Lozano, 1980: 214-215), pero conservando en gran medida la austeridad de su pasado medieval. En los tiempos modernos el inmueble sufrió un proceso de progresivo deterioro hasta que, en el año 1965, fuera restaurado en el contexto de su adaptación a la función museística; ${ }^{8}$ de este modo, en 1971 se instaló allí la sección de Bellas Artes del Museo Provincial de Cáceres, permaneciendo en sus salas hasta 1988. A partir de ese momento los fondos serán depositados en la Casa de los Caballos -la nueva sección de Bellas Artes se inaugura en 1991-, donde compartirán el espacio expositivo con la colección de arte contemporáneo del mismo Museo. En la actualidad el palacio Espadero-Pizarro funciona como sede de la Biblioteca Zamora-Vicente.

Si centramos de nuevo la atención sobre el escudo que corona la puerta principal [2], estudiosos de los aspectos heráldicos del mismo como Cordero Alvarado (1989: 29 y 32) o Bueno Flores (1990: 69-70) lo describen como blasón cuartelado en cruz, con las siguientes armas en sus cuatro campos, de izquierda a derecha y de arriba abajo: Cáceres-Espadero ${ }^{9}$, De los Nidos $^{10}$, Andrade -o Andrada- ${ }^{11}$ y Pizarro ${ }^{12}$. Ambos autores apuntan al respecto que, si tenemos en cuenta los dos primeros cuarteles que conforman tanto este como otros blasones afines conservados en la 


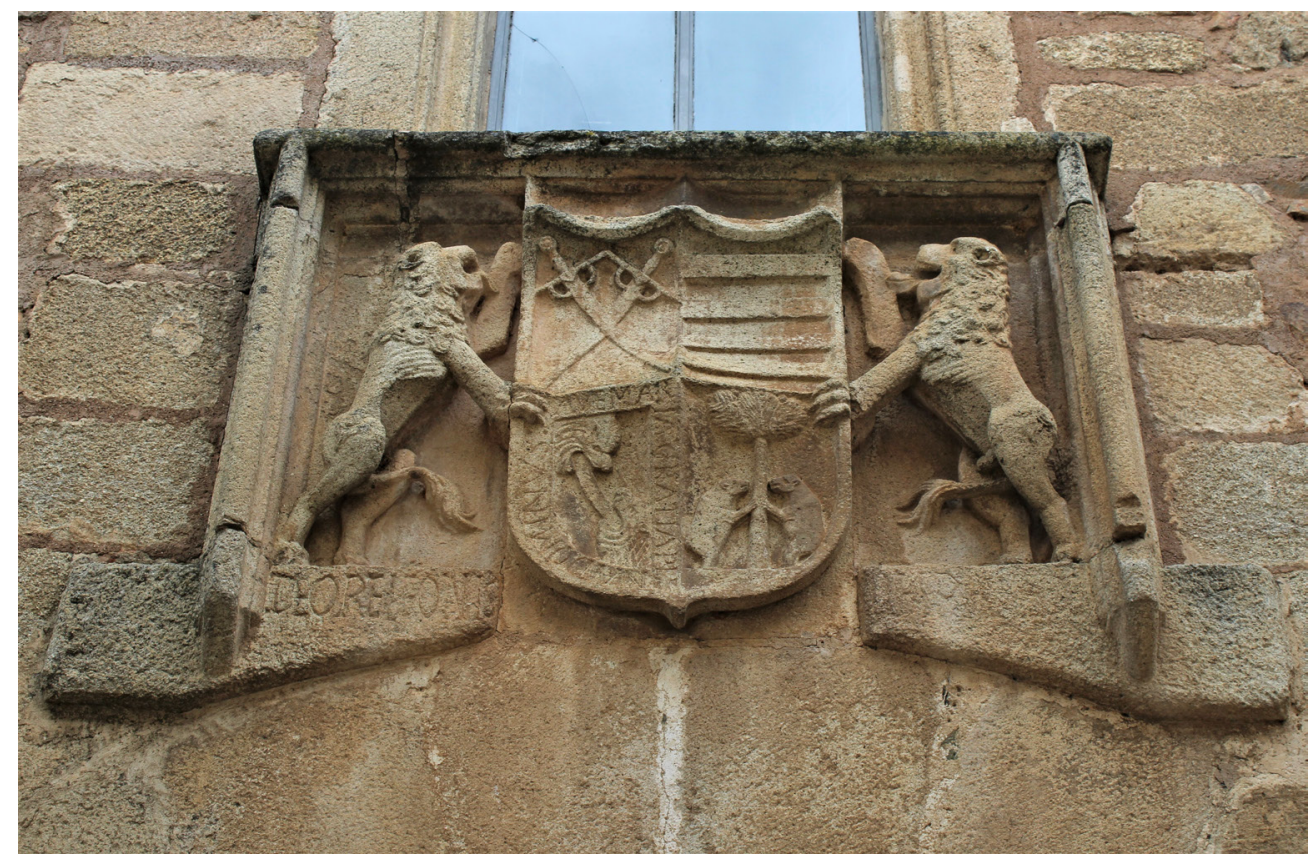

2. Casa-palacio de los Espadero-Pizarro o de Cáceres-De los Nidos, Cáceres. Blasón principal sobre la portada

pequeña ventana de esquina de la torre desmochada o en el patio del edificio, no resulta procedente llamar a esta casa fuerte de los Espadero-Pizarro, sino de Cáceres-De los Nidos, al ser los correspondientes al matrimonio entre Gonzalo de Cáceres Andrada, de la estirpe de los Espadero, y Marina Alonso, de la familia de los Nidos -enlace que muy probablemente daría lugar a la construcción del inmueble-, los que presiden la puerta principal de entrada (Mogollón, 1995b: 120) ${ }^{13}$.

El escudo está sostenido por sendos leones tenantes de cuidada labra; se disponen afrontados y rampantes, con clara indicación de lengua y uñas, como suele ser preceptivo en la representación de estos nobles animales en las armerías. Debe destacarse en ellos el hecho de que el de la derecha presenta el detalle de los genitales -león «entero»-, en contraste con el de la izquierda, que carece de ellos. Tal diferencia podría deberse a la pérdida del atributo masculino en este último o, más probablemente, a la vista de la anatomía más estilizada que presenta en relación a su oponente, a que se tratara en realidad de una leona, siendo por tanto ejemplares de distinto sexo los que flanquean estas armas.

Ambas figuras de felinos descansan, a modo de plataformas, sobre sendas piezas alargadas y salientes del muro, que sirven de sustento a los arranques del alfiz al tiempo que perfilan el extradós de las dovelas superiores del arco de la puerta. Sobre estos elementos se grabó una inscripción en dos partes, de la que solo resulta hoy legible la del lado izquierdo [3]. Indicó en su momento Carlos Callejo Serrano (1980: 102-104) que tal epígrafe venía siendo interpretado tradicionalmente como D. LOPE LEONI, apuntando a continuación que su correcta transcripción había de ser DE ORE LEONIS, sentencia que continuaría bajo el león de la derecha, donde apenas persisten algunas trazas muy borrosas del texto, con un LIBERA NOS, de modo que el significado conjunto de la sentencia sería: «Sálvanos de la boca del león». Entendemos que la propuesta de Callejo Serrano es acertada, si bien queremos matizar ligeramente su lectura analizando con más detalle las distintas posibilidades de continuidad de la primera mitad del texto inscrito.

La opción más probable, si seguimos estrictamente el texto latino de la parte conservada de la inscripción, es la procedente del pasaje evangélico de 2 Tim 4, 17-18, liberatus sum de ore leonis, que se inserta en el siguiente párrafo: «Pero el Señor me asistió y me dio fuerzas para que, por mi medio, se proclamara plenamente el mensaje y lo oyeran todos los gentiles. Y fui librado de la boca del león. El Se- 
ñor me librará de toda obra mala y me salvará guardándome para su Reino celestial» ${ }^{14}$.

Sin embargo, cabe la posibilidad de que la fuente de inspiración de la sentencia no se encuentre directamente en las Escrituras, sino en algún texto devocional derivado de las mismas. Es el caso del responsorio del Oficio de noche, o del Domine lesu Christe del Offertorium de la misa de réquiem o misa de difuntos -Missa pro defunctis o Missa defunctorum-, donde podemos leer:

Señor, Jesucristo, Rey glorioso, liberad las almas de los fieles difuntos de las llamas del Infierno y el profundo abismo. Liberadlas de la boca del león [Libera eas de ore leonis] para que el abismo horrible no las engulla ni sean encadenadas en oscuridad. Que el abanderado san Miguel los guíe a la santa luz, como le prometiste a Abraham y a su descendencia ${ }^{15}$

De igual modo, con un De ore leonis libera me domine et a cornibus unicornium humilitatem meam se inicia uno de los cantos del oficio del Domingo de Pasión, muy probablemente a partir de su reiteración, entre otros lugares, en las orationes y antífonas de la Feria III post Dominicam in Ramis Palmarum del Breviarium Gothicum secundum regulam beatissimi Isidori archiepiscopi hispalensi (edición de Madrid, 1775: 344 y 346).

Otra fuente factible es la exclamación Salva me ex ore leonis procedente del salmo 22, 17-22 -salmo 21 en la Vulgata-, si bien, como puede observarse, sustituyendo la partícula de por ex: «Perros innumerables me rodean, / una banda de malvados me acorrala / como para prender mis manos y mis pies / [...] ¡Mas tu Yahveh, no te estés lejos, / corre en mi ayuda, oh fuerza mía, / libra mi alma de la espada, / mi única de las garras del perro; / sálvame de las fauces del león, / y mi pobre ser de los cuernos de los búfalos!» ${ }^{16}$. Debe tenerse en cuenta, de cara a la posible interpretación de esas palabras en el blasón cacereño, que proceden de la elegía de un justo que se siente alejado de su Dios y se queja de un abandono que considera inmerecido; rodeado de fieros enemigos, presiente la proximidad de la muerte y por ello implora auxilio a su Señor, que parece haber ocultado el rostro a sus sufrimientos. El salmista pide de este modo a Yahveh, su única fuerza y auxilio, que no le ignore, recurriendo para ello a metáforas llamativas y gráficas como las alusiones a las fauces, garras o cuernos de distintos animales feroces o agresivos.

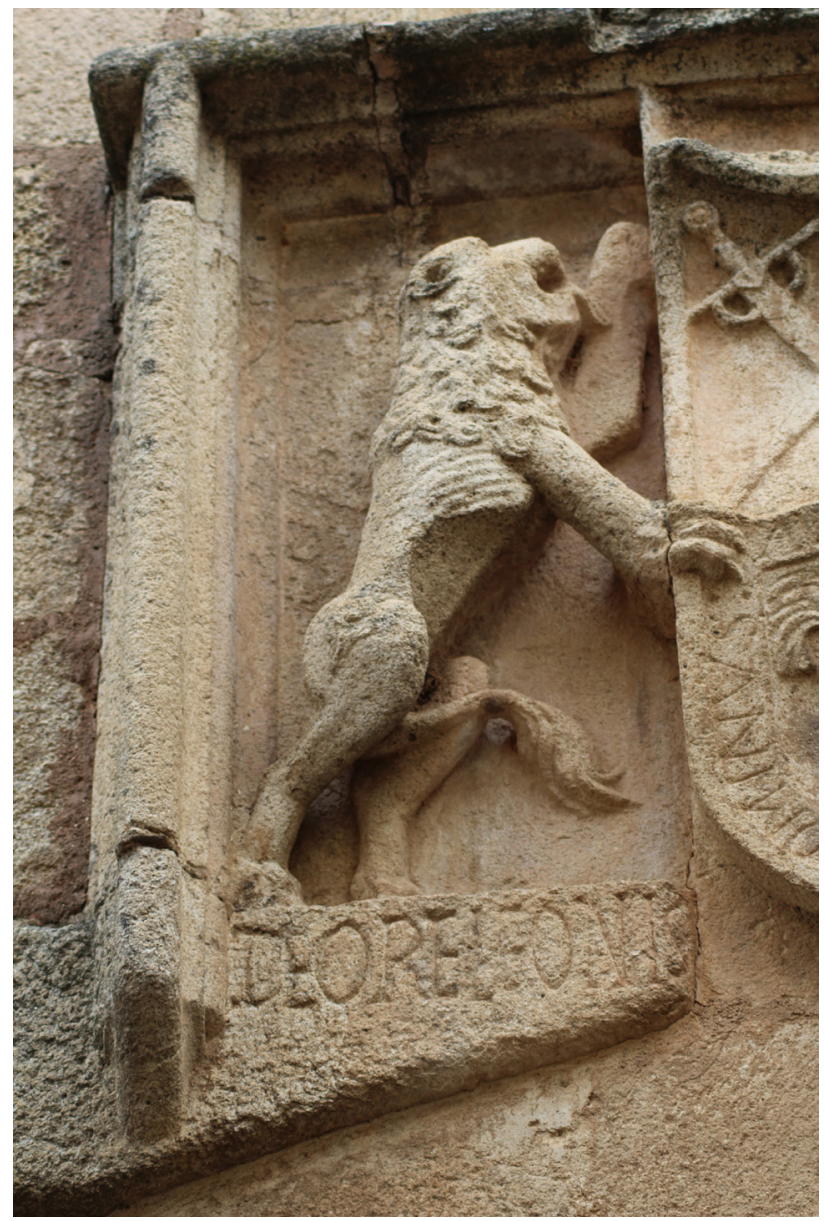

3. Casa-palacio de los Espadero-Pizarro o de Cáceres-De los Nidos, Cáceres. Detalle del león tenante izquierdo e inscripción en la base del blasón principal sobre la portada

No olvidemos mencionar también, por afinidad, la cita de Amós 3, 12, donde se indica: «Así dice Yahveh: Como salva el pastor de la boca del león dos patas o la punta de una oreja, así se salvarán los hijos de Israel, los que se sientan en Samaria, en el borde de un lecho y un diván de Damasco» ${ }^{17}$.

Con independencia de cuál sea la estricta fuente textual del lema de la portada que nos ocupa, ambas referencias bíblicas, a los Salmos y a la Epístola a Timoteo, fueron determinantes a la hora de consolidar el proceso de demonización del león en la tradición cristiana, asunto que sin duda guarda relación con nuestro blasón cacereño. Es por ello que dedicaremos los siguientes párrafos a analizar los fundamentos simbólicos de la figura del león como bestia devorante o maléfica. 


\section{La dimensión demoníaca del león}

Elevado ya en la fabulística clásica a la categoría de «rey de los animales» -por lo que devendrá símbolo de realeza, empleado con mucha frecuencia en la heráldica medieval y moderna-, fue bestia de naturaleza ígnea o solar en las culturas antiguas, a causa muy probablemente del color pardo dorado de su piel y de la vistosa melena del macho a modo de rayos solares: una de las figuraciones del dios egipcio Ra era un león con el disco solar sobre la cabeza. También actuó como frecuente elemento apotropaico, dispuesto como eterno guardián en la puerta de ciudades, templos o en el trono real, lo que justificará su abundante presencia en las portadas de las iglesias románicas. Pero, al mismo tiempo, debido a su notable fuerza y fiereza, fue también portador de poderes catastróficos: Irra, la diosa babilónica de la peste, era representada bajo la forma de un terrible león. La victoria de héroes de la Antigüedad como Hércules sobre este animal representaba el triunfo del espíritu humano sobre la naturaleza bruta. Los textos zoológicos grecolatinos insistirán, además, en la enorme voracidad de este temible depredador (ARIST. HA VIII, 5 (594 b); PLIN. Nat. VIII, 46 (18); AEL. NA V, 39)18. Será imagen habitual de virtudes como la Nobleza, Piedad, Misericordia y también Valentía, si bien los bestiarios y textos medievales insisten al mismo tiempo en el hecho de que diversos pequeños animales o sonidos puedan llegar a infundir profundo terror en el ánimo de tan imponente animal ${ }^{19}$.

De igual modo, el gran félido será en el simbolismo cristiano una figura ambigua, encarnación, por un lado, de la fuerza invencible de la tribu de Judá, pero también imagen del adversario devorador contra el cual solo Dios puede garantizar la protección. Tal ambivalencia se dedujo de los abundantes pasajes de las Sagradas Escrituras -pues en Palestina los leones no resultaban extraños en los tiempos bíblicos- que hacen referencia al animal. Fue, a partes iguales, una bestia admirada y temida. La admiración se dirige fundamentalmente a su bello aspecto, valentía e imponente fortaleza (Pr 30, 30, Jc 14, 5-7, Jc 14, 18; 2 S 1, 23; 17,10; Est 4,17s ${ }^{20}$, siendo igualmente su majestad imagen de la dignidad real (Ez 19, 1-9; $1 R$ 10, 18-20; Ap 5, 5) o referencia a la confianza vital del hombre justo, que nada ha de temer $(\operatorname{Pr} 28,1)$.

Pero el león es, al mismo tiempo, una criatura que suscita los más profundos temores: puede amedrentar a cau- sa de sus potentes mandíbulas $(J / 1,6)$ o cuando, como un "devorador de naciones", abandona su guarida o su bosque (Jr 4, 7; 25, 38; 49, 19). No extraña que tan formidable criatura se mencione en diversos lugares como instrumento o imagen de la justicia punitiva de Yahveh (1 R 13, 24-28; 20 , 36; Si 27, 28), que, en determinados momentos, en especial cuando defiende a Israel contra sus asaltantes, se comporta como un fiero león (Jr 5, 6; Is 31, 4) ${ }^{21}$.

Poder al servicio de Yahveh, esta bestia puede ser al mismo tiempo imagen de las fuerzas maléficas. Lo encontramos como alegoría de tiranos -los reyes de Asiria y Babilonia-, comparados a leones que se abaten sobre Israel, Grex dispersus o «rebaño disperso» (Jr 50, 17; cf. Si 13, 19 o Pr 28, 15). En los Salmos estos animales son equiparados a los adversarios perseguidores e implacables (Sal 7, 2-3) o a los impíos que emplean la táctica de la fiera para mantenerse al acecho de los desdichados (Sal 10, 8-9; 17, 12; Is 35, 9). Puede aparecer también como alusión al mundo subterráneo como un abismo devorador o imagen de la muerte, cuando el hombre percibe en su angustia mortal la visión de leones rugientes que abren sus fauces contra él (Sal 22, 14; 22, 22). La situación de quien se encuentra aprisionado entre los bienes terrenos es comparada en varias ocasiones por salmistas y profetas a una permanencia entre estas fieras $(\mathrm{Sal} 35,17)$. Ser entregado a la muerte significa contemplar el rostro del feroz animal, como muestra el conocido relato de Daniel en el foso de los leones ( $D n$ 6, 17-25 -16-24 en la Vulgata-).

Este episodio, o aquél en que Sansón desgarra las fauces de un león (Jue 14, 5ss), se consideran prefiguraciones de Cristo superando el abismo y las oscuras potencias del mundo subterráneo ${ }^{22}$. Aunque ya en el Antiguo Testamento el gran félido presenta una clara orientación diabólica en ciertos momentos ${ }^{23}$, es en las cartas apostólicas donde deviene de manera definitiva símbolo del poder de las tinieblas ( $1 P 5,8$, o el texto ya reproducido de $2 \operatorname{Tm} 4,17$ ). En este mismo sentido, algunos de los más temibles rasgos físicos del león se atribuyen a las imponentes bestias híbridas del Apocalipsis: dientes (Ap 9, 8), cabeza (Ap 9, 17), boca (Ap 13, 2) o rugido $(A p \text { 10, 3) })^{24}$.

Pero, a pesar de estas referencias, en la literatura cristiana el león será usado raramente como encarnación o poder diabólico, por ser también símbolo de Cristo o del evangelista san Marcos. Es por ello que los comentaristas 
4. Giovanni Bono de Bissone, león estilóforo sujetando entre sus garras a un oso y un ave

c. 1283. Cremona, catedral, vestíbulo de la entrada principal

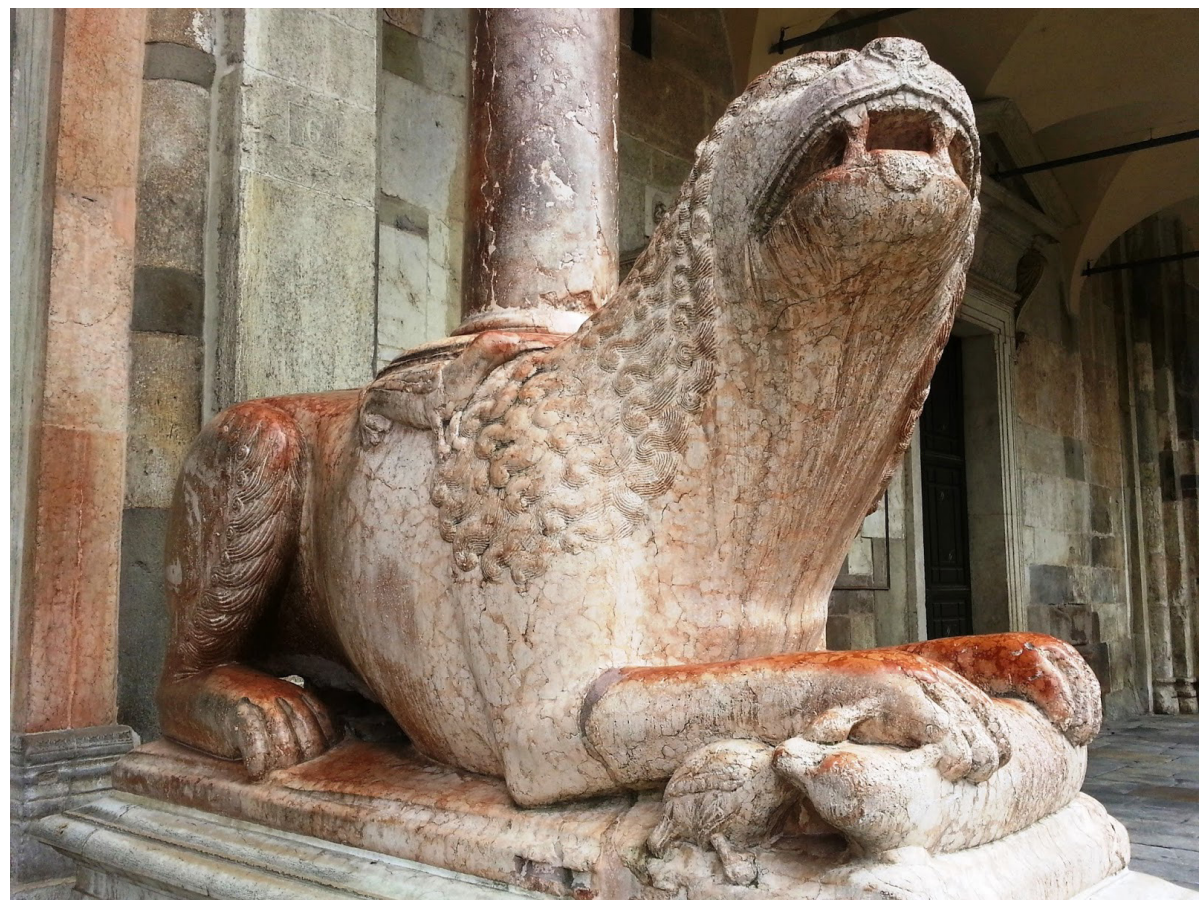

pondrán de manifiesto sin ambigüedades la doble vertiente de la orientación simbólica del animal. Agustín de Hipona, por ejemplo, escribe:

Llevó [Jesucristo] nombre de león y fue inmolado como cordero: león por su fortaleza, cordero por su inocencia; león por lo invencible, cordero por lo manso; y este cordero, muerto, con su muerte derribó al león que nos ronda, buscando presa; que también al diablo se le llama león, no por fuerte, sino por feroz (AVG. Serm. 263, 2; cf. 1 P 5, 8; Agustín de Hipona, 1964: 350).

Y Gregorio Magno escribe en sus Morales:

El león posee fuerza y crueldad. Por su fuerza designa al Señor; por su crueldad al demonio. Se dice sobre el Señor: 'Ha vencido el león de la tribu de Judá, el renuevo de David' (Ap $5,5)$. Sobre el diablo está escrito: 'Vuestro enemigo, como león rugiente, ronda buscando a quien devorar'. Con el nombre de leona se designa unas veces a la Santa Iglesia y otras a Babilonia. Notando su audacia frente a la adversidad, simboliza a la Iglesia, como confirman las palabras del mismo Job que, hablando de Judea, abandonada por la Iglesia, dijo:
'No la pisaron los hijos de los mercaderes, ni anduvo por ella la leona' (Jb 28, 6). En otras ocasiones, con el nombre de leona se alude a la ciudad de este mundo, Babilonia, que se enfurece con desmesurada crueldad contra la vida de los inocentes. Asociada al antiguo enemigo como a fiero león, concibe las semillas de su perversa persuasión y engendra de sí hijos culpables, semejantes a él como cachorros crueles. Los engendrados réprobos a una vida de maldad, por la culpa de los espíritus malignos, son cachorros de león (GREG. Mor. V, 41; Gregorio Magno, 1998: vol. I, pp. 329-330).

Algo más adelante añade:

Los santos, mientras aún están en esta vida, se custodian a sí mismos con solícita circunspección para que el león que ronda con sus insidias no los sorprenda, esto es, para que el antiguo enemigo, disfrazado de cualquier virtud, no los mate; para que el bramido de la leona no importune sus oídos, esto es, para que la gloria de Babilonia no aparte su sentimiento del amor de la patria celeste; para que los dientes de los cachorros no les muerdan, esto es, para que la persuasión de los réprobos no crezca en su corazón (GREG. Mor. V, 2; Gregorio Magno, 1998: vol. I, p. 330). 


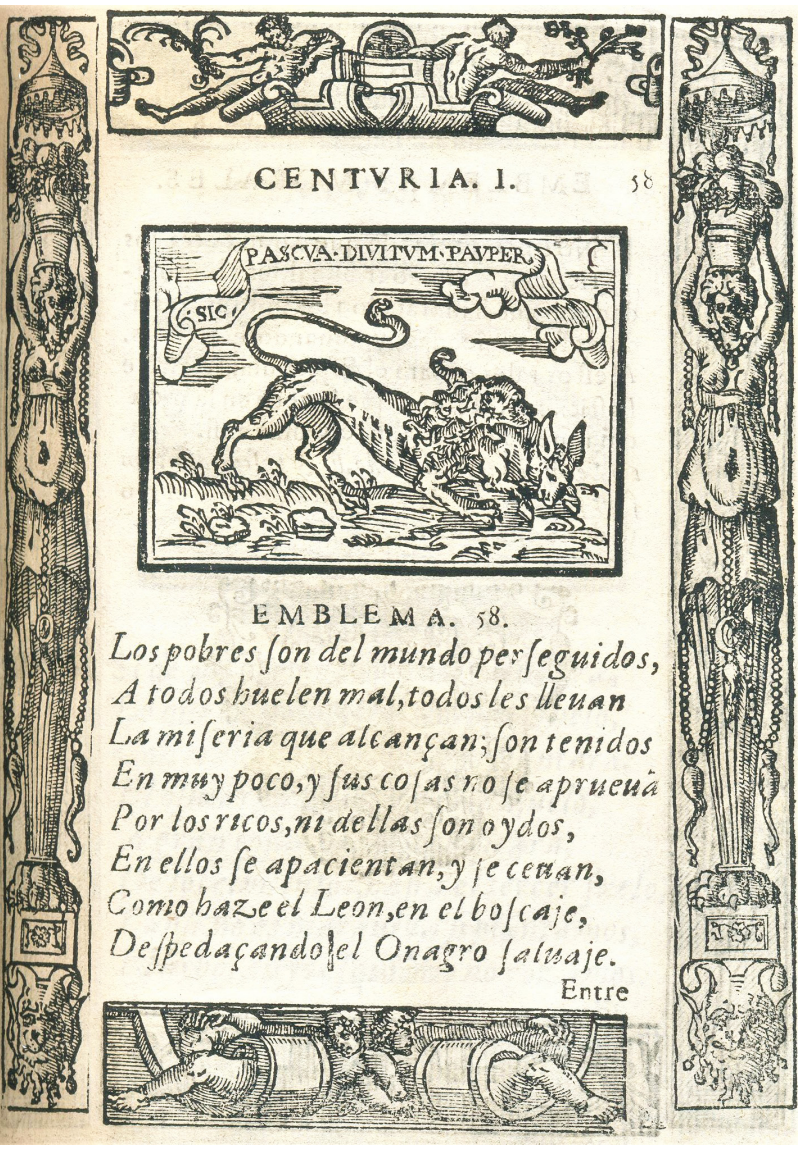

5. Sebastián de Covarrubias, Emblemas morales, Madrid, 1610. Centuria I, emblema 58

Las alegorizaciones del león en las distintas versiones del Fisiólogo son esencialmente cristológicas, estableciéndose un triple paralelo entre distintas propiedades naturales asignadas al animal y otras tantas atribuciones del Mesías. Sin embargo, en algunos bestiarios encontramos un significado opuesto: como señala Mariño Ferro (1996: 280), el león que busca una presa significa en el Bestiario Valdense al Demonio que acecha al pecador.

En el imaginario del arte medieval, y concretamente en la escultura románica, abundan los ejemplos de leones antropófagos; dentro de esta categoría se incluyen los denominados estilóforos que, al tiempo que destrozan a un individuo entre sus fauces o sujetan a diversos animales con sus garras, se ven aplastados bajo el peso de la columna, es decir, constituyen las fuerzas infernales vencidas por el poder de Cristo y la Iglesia [4]. Las fauces de Leviatán como entrada al Infierno adquieren en no pocas ocasiones los rasgos de la cabeza del león: el combate en el Antiguo Testamento de figuras cristológicas como Sansón y David, representará la lucha contra el Anticristo -un león- cuyos dientes - la boca del infierno- tratan de desgarrar a los hombres fieles. En diversas versiones artísticas de La tentación de san Antonio Abad los leones forman parte de la caótica legión de criaturas demoníacas que tientan y atormentan al santo ${ }^{25}$.

El majestuoso animal suele asociarse en la Edad Moderna a la representación de la Soberbia, la Ira y el Temperamento colérico (Tervarent, 2002: 327$)^{26}$. En cuanto a los Hieroglyphica de Horapolo, «Para expresar 'temible', utilizan el mismo signo [un león], porque, siendo este animal el más poderoso, hace temer a todos los que lo ven" (Hierog. I, 4, 4; González de Zárate, 1991: 110)²7. Es por ello que para Cesare Ripa el Terror se figura mediante un hombre con cabeza de león, «[...] por ser propio del León aterrorizar a quien lo mira, acostumbrando por ello los antiguos a representar el terror otorgándole el rostro de esta fiera» (1987: vol. II, pp. 358-359). No faltan emblemas que aluden a la naturaleza más violenta o irascible del animal: además del ejemplo ya citado de Andrea Alciato, en el que el gran félido acorralado por perros y cazadores es expresiva imagen de la ira descontrolada, Sebastián de Covarrubias recurre a la imagen del león que devora a un onagro o asno salvaje como adecuado trasunto de los ricos y poderosos que tratan con crueldad a los más desfavorecidos (1610: centuria I, emblema 58, fol. 58) [5] $]^{28}$.

Retornando ahora a las armas del palacio cacereño, entendemos que, para su correcta valoración, ha de tenerse en cuenta el contexto de la cita bíblica en que se inspira. Si confirmamos que la fuente literaria de la sentencia es Sal 22, 17-22, tales versos constituyen, como ya adelantamos, un clásico referente bíblico al «Sufrimiento y esperanza del justo», fragmento de la oración de un inocente que clama por su liberación ante la amenaza de sus más poderosos enemigos. De este modo, los leones tenantes pasarían de ser elemento protector de los cuarteles heráldicos que sustentan con sus patas -como es habitual en estos casos- a convertirse en figura agresiva y amenazante, bien de naturaleza espiritual, bien como referencia a oponentes más materiales y concretos, encarnados en las familias o grupos contrarios a los intereses de los titulares de la casa-palacio. 


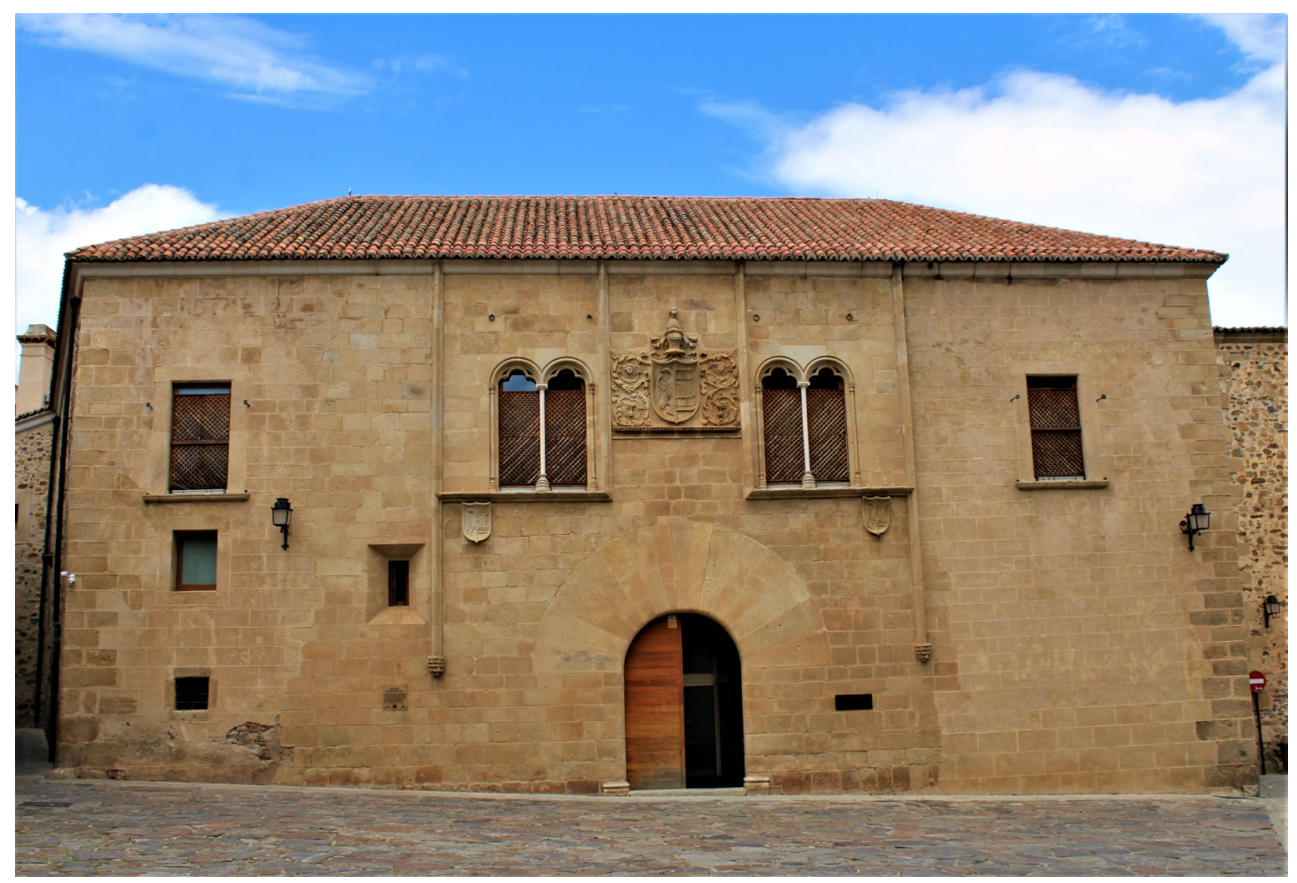

6. Palacio de Mayoralgo, Cáceres. Vista general de la fachada principal actual

\section{El blasón de los Blázquez en el palacio de los Mayoralgo}

El palacio del linaje de los Mayoralgo -o condes de la Torre de Mayoralgo- es otro de los hitos destacados en el paisaje arquitectónico del casco antiguo cacereño, tanto por su ubicación y características constructivas, como por la relevancia del linaje responsable de su construcción y evolución. Constituye un elocuente testimonio de una sociedad local bajomedieval dominada por grupos nobiliarios con importantes haciendas, notable influencia en el gobierno de la ciudad mediante la ostentación de cargos concejiles y una activa intervención en la política de la época (Mogollón, 1995a: 117-119).

Edificio también de planta trapezoidal un tanto irregular, ocupa un amplio solar en un significativo enclave dentro de la ciudad intramuros, próximo a la entrada del Arco de la Estrella, entre el adarve de la muralla y la plaza de Santa María, a la que hoy abre su puerta principal. Es un inmueble complejo en su devenir constructivo, con sucesivas ampliaciones y evidentes transformaciones operadas a lo largo del tiempo que confieren irregularidad a la distribución de sus estancias. Pueden distinguirse sin embargo, como han puesto de manifiesto los diversos investigadores que se han ocupado del palacio, dos momentos principales en la evolución de su arquitectura.

Una primera fase puede situarse en la segunda mitad del s. XIV ${ }^{29}$. A este periodo correspondería la mayor parte de la fábrica, con las habitaciones distribuidas en torno a un patio pequeño e irregular que presenta en dos de sus lados galerías porticadas de arcos apuntados de ladrillo sobre gruesos pilares con aristas en chaflán y capiteles troncopiramidales con ruda decoración vegetal un tanto arcaizante ${ }^{30}$. En esos mismos años puede fecharse la antigua fachada del edificio, o frente lateral que da a la calle del Arco de la Estrella, reformada posteriormente con ventanas adinteladas, pero donde se conserva la que sería antigua puerta de entrada, vano abierto en arco apuntado con moldurado bocel que apoya en sencillos capiteles góticos con decoración vegetal. También en este flanco se conserva un escudo con media águila y una tore minuciosamente labradas en sus detalles que, fechado en 1340, constituiría el más temprano testimonio heráldico de los Blázquez-Mayoralgo y, tal vez, el más antiguo escudo arquitectónico de la ciudad (Floriano 1950: 58)31. 


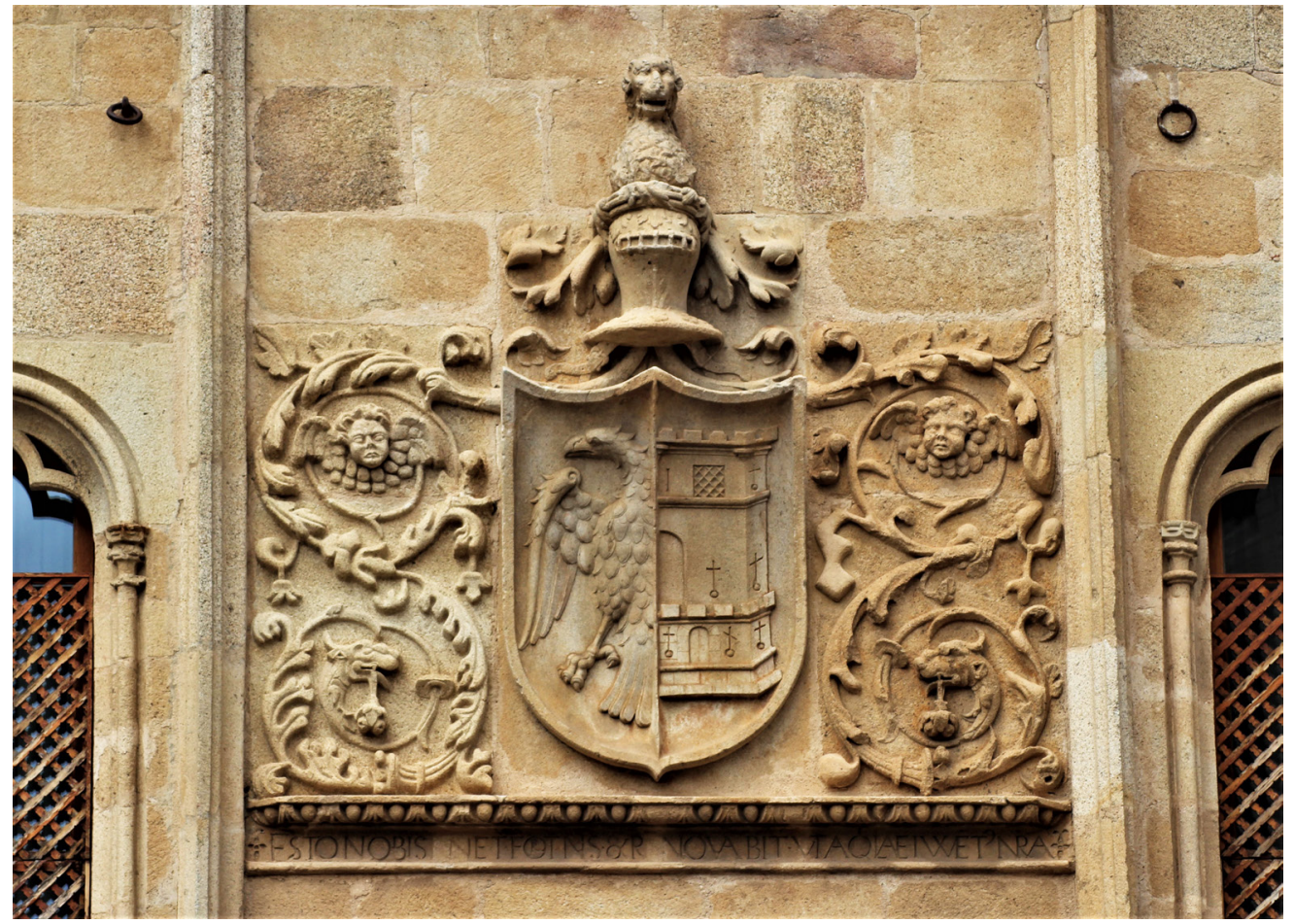

7. Palacio de Mayoralgo, Cáceres. Blasón de los Blázquez-Mayoralgo sobre la portada principal

La segunda etapa constructiva se inicia en el año 1534, cuando tiene lugar la realización de una nueva fachada principal que da a la plaza de Santa María, proyecto de acondicionamiento de este frente del edificio que ha de entenderse en el marco del proceso generalizado de adaptación de antiguas casas de modestas dimensiones y carácter eminentemente castrense a mansiones más espaciosas y habitables que se está produciendo en el conjunto monumental cacereño ${ }^{32}$. De acuerdo con De Mayoralgo y Lodo (2004: 118-119), fue Paulo de Mayoralgo quien acomete esa importante obra, que suponía al mismo tiempo una remodelación a gran escala de todo el inmueble a costa de la adquisición de casas colindantes y alguna calleja pública, en una clara combinación de elementos góticos y renacentistas.

Es esta nueva fachada [6] una estructura de grandes proporciones, caracterizada formalmente por una rígida simetría que le confiere armonía y belleza formal al tiempo que aporta sobria monumentalidad a la plaza de Santa María. De cantería la zona central y esquinas, y de mampostería enfoscada las superficies laterales, este amplio paramento frontal, de aspecto macizo en su cuerpo inferior al abrirse los vanos en el superior, se articula mediante la compartimentación generada por un juego de alfices, de modo que se combinan uno recto envolvente con otro que se quiebra en el espacio interior para enmarcar las elegantes ventanas geminadas que flanquean el gran escudo central. Finamente moldurados, estos vanos presentan arcos de medio punto con intradós trilobulado y tracería calada, que descansan en un estilizado mainel central de mármol.

La puerta, perfectamente centrada, se abre en arco de medio punto con grandes dovelas radiales planas. Sobre ella, entre las ventanas descritas, se dispone el gran escudo de Mayoralgo [7] con las armas familiares - «en campo de oro, un partido dimidiado de águila y torre»-, timbradas por un yelmo afrontado, con un león por cimera y el jefe apuntado al estilo florentino ${ }^{33}$. Bajo el casco, nacen del burlete dos sartas de lambrequines que terminan en cabezas de querubines los superiores y en monstruos los inferiores, todo ello, como se ha señalado, de clara inspiración plateresca (Cordero, 1991: 59) ${ }^{34}$. Bajo ambas ventanas se repite, con un formato más simplificado y reducido, el escudo familiar ya descrito. 


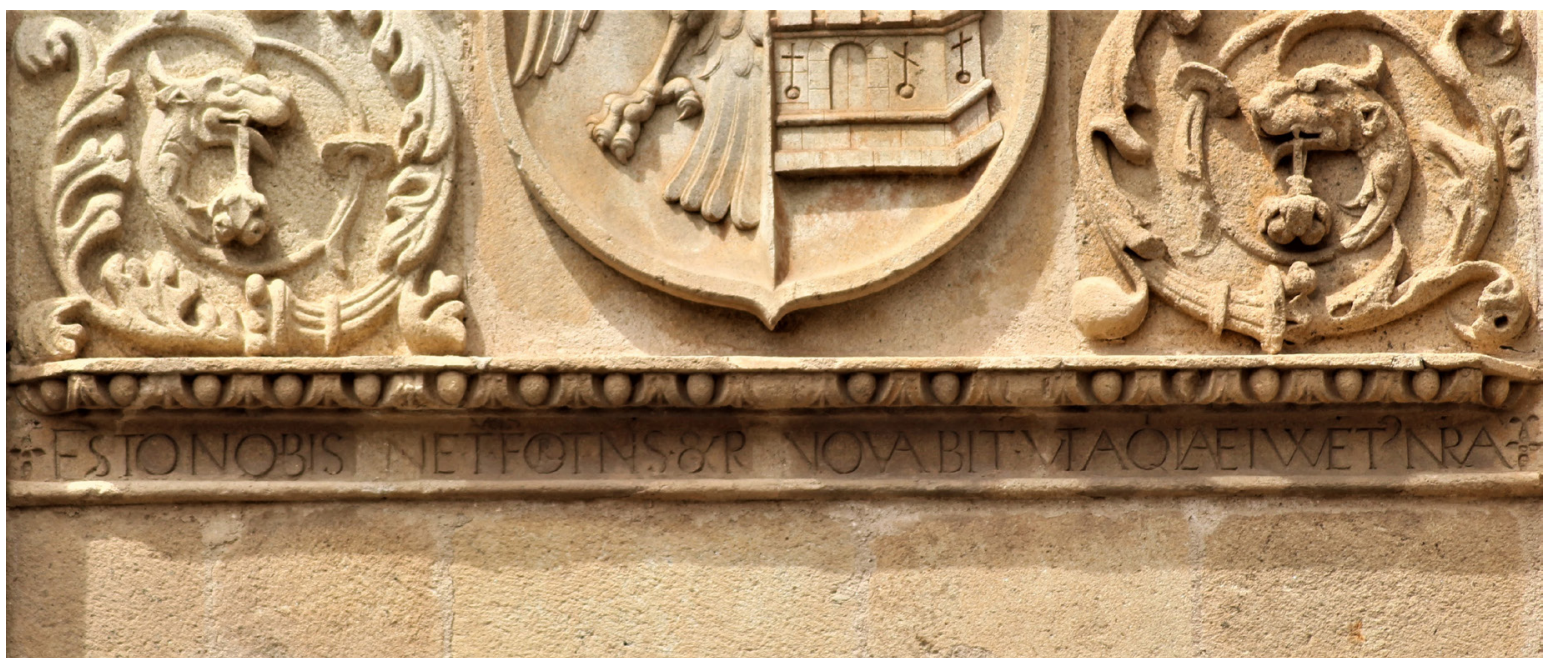

8. Palacio de Mayoralgo, Cáceres. Detalle de la inscripción bajo el blasón principal de los Blázquez-Mayoralgo

En julio de 1937, en plena Guerra Civil, la fachada principal y la primera crujía quedaron destruidas como consecuencia de un bombardeo aéreo; afortunadamente, el gran escudo principal cayó en un solo bloque y resultó intacto salvo algunos daños menores en los lambrequines de la parte derecha. Este frente será reconstruido por la Dirección General de Bellas Artes siguiendo y respetando fielmente el modelo original, y experimentando después nuevas reformas emprendidas por la familia propietaria, especialmente en los años 1959-60. En 1992 el inmueble fue adquirido como Centro de Gestión Catastral y Cooperación Tributaria del Ministerio de Economía y Hacienda, aunque permanecería sin ser ocupado desde entonces; posteriormente fue vendido a la Caja de Ahorros de Extremadura, de la que es en la actualidad, tras una profunda remodelación, sede institucional.

Debajo del referido blasón principal, en una suerte de cornisa de ovas renacientes que cierra su enmarque por la parte inferior, se dispone una cuidada inscripción que reza: ESTO NOBIS [D]NE T FORTNS \& RENOVABIT VT AQILAE IVVET') NRA, CUya transcripción sería: Esto nobis Domine turris fortitudinis et renovavit ut aquilae iuventutem nostram, y que puede traducirse: "Sé tú Señor para nosotros torre de fortaleza y se renovará, como la del águila, nuestra juventud» [8]. Se trata de un lema híbrido, formado por dos partes de distinto origen que, como acabamos de ver, hacen referencia a sendos motivos demediados en el blasón: el águila y la torre. En primer lugar, Esto nobis Domine turris fortitudinis se ins- pira aparentemente en Sal 61, 4 -60, 3-4 de la Vulgata-: Deduxisti me, quia factus es spes mea, turris fortitudinis a facie inimici [«A la roca que se alza lejos de mí, condúceme / pues tú eres mi refugio, torre fuerte frente al enemigo»] ${ }^{35}$. Con la misma configuración que en el palacio cacereño tal frase aparece, por ejemplo, en numerosas oraciones de la liturgia cristiana; así en la Conclusio de la Litaniae sanctorum, en la antífona del Itinerarium clericorum incluido en el Breviarium romanum ex decreto Sacrosancti Concilii Tridentini, o en los oficios del cuarto domingo de Cuaresma o del miércoles de ceniza. De igual modo, bajo esa misma fórmula figura como lema del título de conde de la Vega Grande de Guadalupe.

En cuanto a la segunda parte de la sentencia, renovavit ut aquilae, juventutem nostram, la fuente literaria parece encontrarse en Sal 103, 5-102, 5 de la Vulgata-, donde leemos: qui replet in bonis desiderium tuum: renovabitur ut aquilae juventus tua [«satura de bienes tu existencia, mientras tu juventud se renueva como el águila»], salmo que constituye una alabanza de la misericordia divina hacia el género humano a través de la Creación, de modo que, en su benevolencia, no se limita a salvarnos de peligros y dolencias y a perdonar nuestras culpas, sino a colmarnos de bienes; de este modo puede afirmarse de manera figurada que nuestra juventud se renueva constantemente como la del águila, ave que, de acuerdo con su remota tradición legendaria, cambia su plumaje cada año y rejuvenece su aspecto. 


\section{El águila como emblema de renovatio}

Para entender la vinculación de las propiedades naturales atribuidas al águila con el concepto cristiano de renovación espiritual ${ }^{16}$ nos tenemos que remontar, en primera instancia, a los textos de la zoología clásica. El tópico arranca concretamente de una información de Aristóteles de Estagira, quien escribe al respecto: «A las águilas, a medida que van envejeciendo les va creciendo la punta del pico que se curva cada vez más, y al fin acaban por morir de hambre» (Hist. an., IX, 32, 619a; Aristóteles, 1990: 513)37, opinión coincidente con la que Plinio el Viejo expondrá en su Historia natural: «No mueren [las águilas] de vejez ni de enfermedad, sino de hambre, al crecerles tanto la parte superior del pico que la curvatura no permite que se abra» (Nat. hist., X, 15; Plinio, 2003: 359). Sin duda tales afirmaciones sustentarán la interpretación alegórica de Horapolo del Nilo, al entender este que la imagen de un águila con el pico torcido fue entre los egipcios jeroglífico del "viejo que se muere de hambre», pues esta ave, «[...] cuando envejece, se le tuerce el pico y muere de hambre» (Hierog. II, 96; González de Zárate, 1991: $520)^{38}$. El giro definitivo de esta creencia se produce cuando las referencias de la Antigüedad pagana se funden con la posibilidad de una renovación cíclica del ave, tal y como se sugiere en algunos lugares de las Sagradas Escrituras, en una aparente trasposición a la rapaz de propiedades atribuidas también desde antiguo al mítico ave fénix. Así, al ya citado pasaje de Sal 103, 5, podría sumarse el procedente de Is 40, 31: «[...] mas los que esperan en Yahveh renuevan sus fuerzas, / tienen alas de águila, / corriendo no se fatigan, / caminando no se agotan». La síntesis de ambas tradiciones permitió la configuración de la difundida leyenda cristiana del rejuvenecimiento del ave cuando alcanza su vejez. Encontramos ya la narración completa en las diversas traducciones del Fisiólogo. Por ejemplo, en la versión latina Y del opúsculo, después de citar el mencionado versículo de los Salmos, se afirma:

El Fisiólogo dice que al envejecer el águila, se le tornan de plomo las alas y se le cubren de tinieblas los ojos. ¿Qué hace entonces? Busca una fuente de agua, vuela por los aires hacia el sol, quema en él sus alas y la oscuridad de sus ojos, baja luego a la fuente, se baña tres veces en ella y queda rejuvenecida y renovada.
Tan fabulosas propiedades del ave se convierten aquí en una alegoría de la regeneración mediante el Bautismo:

Así también tú, si tu ropaje ha envejecido y se han oscurecido los ojos de tu corazón, busca la fuente espiritual, que es el Señor [...], y volando hacia la altura, llega hasta el sol de justicia, que es Jesucristo [...]; él quemará tu viejo ropaje diabólico [...], y bautizaos en la fuente sempiterna, despojaos del hombre viejo y de sus actos, y revestid el nuevo que fue creado según el Señor (Phys. 8; Guglielmi y Ayerra, 1971: 46)39.

En las versiones griegas del texto, más allá de alguna leve variación narrativa en el proceso de rejuvenecimiento del ave, el relato es interpretado como una alusión al sacramento de la Confesión de los pecados, con lo cual ya tendríamos confirmadas las dos principales vertientes simbólicas de la regeneración del águila (Ad Phys. 6; Sebastián López, 1986: 39-40) ${ }^{40}$. Testimonio de ello es la alusión indirecta que Agustín de Hipona hace a la narración del Fisiólogo en su comentario del salmo citado:

[...] se dice que el águila, cuando llega a la vejez corporal, no puede tomar alimentos debido al desmesurado crecimiento del pico, que se encorva sobre la parte inferior [...]. Hallándose en estos aprietos, se dice que el águila, por cierto medio natural, debido a la necesidad de renovar su juventud, frota y golpea contra la piedra la parte superior de su pico, la cual, por haber crecido demasiado, la impide comer; desgastándole, pues, en la piedra, se deshace de él, y se ve libre del impedimento anterior del pico que no le dejaba comer. Ahora come, y se restablecen todos sus miembros; después de la vejez será como águila joven, pues vuelve la fortaleza a todos sus miembros, el brillo a sus plumas, el poder a sus alas; vuela como antes en las alturas, y en ella se da cierta resurrección [...]; así también lo que se dijo del águila no sirve para restaurar la inmortalidad del águila, sino para que nos restauremos nosotros en orden a la vida eterna, pues se adujo la semejanza de ella para que la piedra nos despoje de lo que nos impide conseguir la inmortalidad. Luego no presumas de tus propias fuerzas; la firmeza de la piedra lanza de ti la vejez, y la piedra era Cristo (Enarr. in Ps., 102, 9; Agustín de Hipona, 1964-1966: 687-688)¹.

También Jerónimo menciona el cambio de plumas que la vieja águila experimenta en su proceso de rejuvenecimien- 
to (Commentarii in lesaiam XII; Migne, PL, vol. 24, col. 426), y Eutimio compara esta mutación del ave con la renovación cristiana por medio de la Penitencia (Commentarii in psalmum 102).

Pero, más que en la patrística, el relato alegorizado del Fisiólogo encontrará su lugar en el género de los bestiarios bajomedievales, que suelen proponer en sus capítulos dedicados al águila una proyección del relato de aquel viejo texto con ocasionales variaciones y adiciones generadas por la fecunda imaginación medieval. El proceso de rejuvenecimiento del ave constituye igualmente en estos textos una fabulación de la renovación del cristiano por medio del Bautismo en la «fuente espiritual de Dios», o bien de la regeneración de sus pecados a través de la Penitencia (George y Yapp, 1991: 142). En sus ejemplares ilustrados, el relato de la renovación del águila es representado conforme a un esquema convencional que se repite en la mayor parte de ellos. Configura de este modo una triple escena en la que aparece el ave desarrollando otras tantas acciones: 1) capturando un pez, plasmación gráfica de un comentario de Isidoro de Sevilla (Orig. XII, 7, 10-11) ${ }^{42}$ que se inspira a su vez en Plinio (Nat. hist. X, 8); 2) dirigiéndose directamente hacia el sol; y 3) sumergiéndose en un estanque; estos dos últimos detalles recogen, por tanto, sendos momentos clave del ritual de renovación a través del poder purificador del calor del sol y del agua descrito más arriba [9].

Enciclopedistas bajomedievales, como Tomás de Cantimpré (De nat. rer. I, 23) o Alexander Neckam (De nat. anim. VI, 1) reproducen también la narración del Fisiólogo, pero suavizando los detalles más fabulosos en un intento de explicar racionalmente el proceso, si bien mantienen su alegorización como imagen de la renovación, ya sea a través del agua bautismal, ya sea por medio de las lágrimas del arrepentimiento o penitencia.

A causa de la popularidad del asunto en los siglos del medievo, la literatura simbólica moderna se hará eco de tan llamativa propiedad del águila: es el caso de una obra tan influyente como los Hieroglyphica de Pierio Valeriano, autor que recoge la leyenda del rejuvenecimiento del ave a partir de diversas autoridades medievales, así como la manera en que esta elimina la excesiva curvatura de su pico gracias a la auctoritas de Agustín de Hipona. Todo ello convierte a la reina de las aves, según este autor, en jeroglífico de «La juventud renovada», entendiéndose con ello «[...] la limpieza

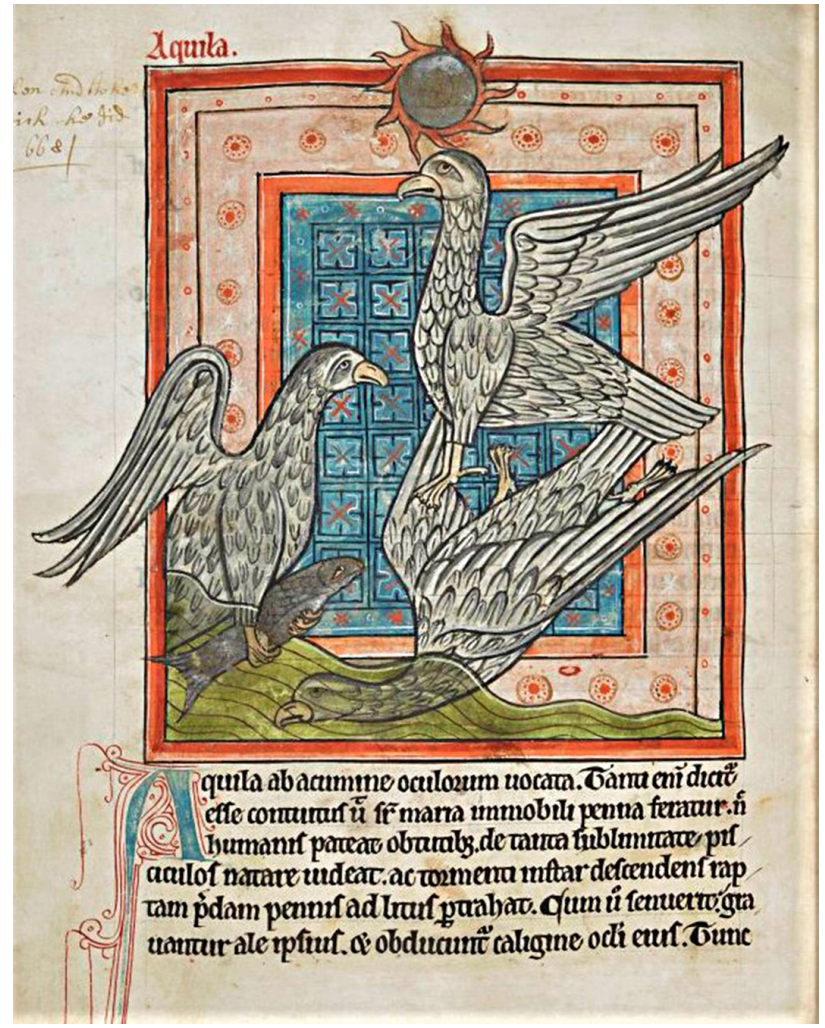

9. Proceso de rejuvenecimiento del águila. Bestiario latino, segundo cuarto del s. XIII, Londres, British Library, Harley MS 4751, fol. 35v

de ánimo, porque nuestro cuerpo camina de la adolescencia hacia la vejez, y así este hombre exterior se debilita y falla en el trabajo, pero el interior tanto mayor fuerza adquiere, y se renueva, cuanto más se afirma en la meditación, y en el ejercicio de la justicia y la honestidad» (1567: lib. XIX, p. $241)^{43}$. Sin duda, ese viejo relato y sus seculares alegorizaciones cristianas se verán reactivadas a fines del quinientos gracias fundamentalmente a las ediciones greco-latinas ilustradas del Fisiólogo atribuido a Epifanio que llevará a cabo Gonzalo Ponce de León, y que ven la luz en Roma en 1587, y en Amberes en $1588^{44}$.

Todo este amplio sustrato literario y cultural explica que el mencionado relato del águila se convierta en lugar común de la literatura emblemática de la segunda mitad del s. $\mathrm{XVI}$, siempre bajo la idea de la renovación cristiana por medio de la penitencia o la resurrección después de la muerte. Entre los diversos ejemplos podemos mencionar una de las Empresas morales de Juan de Borja (1580: empre- 


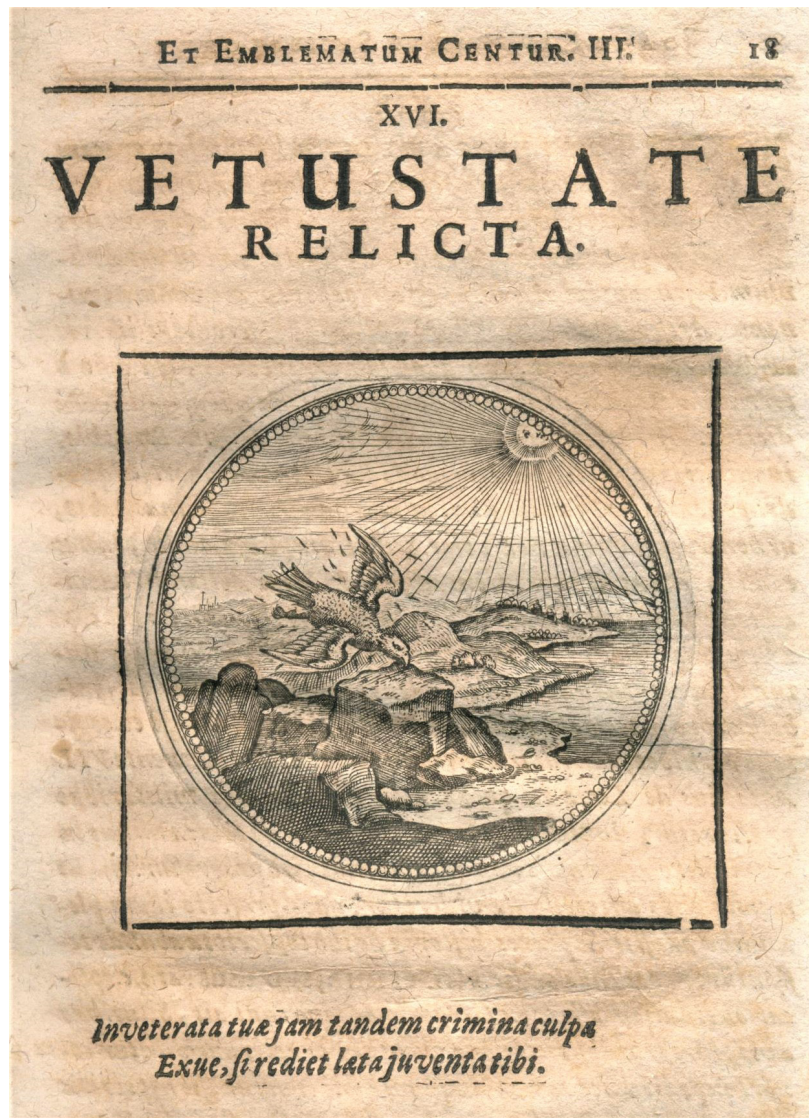

10. Joachim Camerarius, Symbolorum et emblematum ex volatilibus et insectis desumptorum centuria tertia, Frankfurt, 1654. Emblema 16

sa 6, Vetustate relicta -«Una vez abandonada la vejez»-), o un emblema de Nicolás Reusner (1581: lib. II, emblema 38, pp. 101-102, Renovata iuventus), quien escribe al respecto: «Quien es piadoso, y se purifica en la sagrada fuente de la salud, nunca es herido por el fulmíneo fuego de Júpiter. Y así la fe verdadera es protegida por la voluntad celeste, y la luz la atrae en seguida con su resplandor. Cristo es el Sol de Justicia, y la vida eterna, que mantendrá a salvo a quien descubra con un corazón sencillo». Ambas etapas del proceso de rejuvenecimiento -la pérdida de las plumas y la ruptura del viejo pico- aparecen fundidas en la pictura de uno de los emblemas ornitológicos del alemán Joachim Camerarius (1654: emblema 16, fols. 18r y v), que reitera el lema de la empresa de Borja, y en cuyo epigrama nos advierte: «Arranca ahora, finalmente, los viejos pecados de tu culpa, si quieres que vuelva a ti la alegre juventud» $[10]^{45}$.
En consecuencia, la aplicación de las sentencias bíblicas ya referidas al blasón Blázquez-Mayoralgo constituye aquí una proclamación pública del propósito de aquella familia de fundamentar su fe en la fortaleza de Dios con el fin de garantizar una permanente renovación, tal vez no tanto de cariz espiritual como referida a la continuidad de la preminencia del linaje, o a su futura perpetuación en el tiempo.

En las páginas precedentes nos hemos aproximado a un fenómeno que, hasta donde sabemos, aún no había sido objeto de análisis detenido por parte de estudiosos e investigadores como es el de las sentencias o textos epigráficos vinculados a los elementos heráldicos en las fachadas de la arquitectura civil cacereña ${ }^{46}$. Cierto es que se ha mencionado con frecuencia ese hecho en la bibliografía precedente, refiriendo la presencia de tal o cual inscripción, junto con su transcripción y traducción de la misma, pero sin entrar a fondo en las razones y trasfondo significativo de tales asociaciones. Debemos reconocer que un análisis como el que llevamos a cabo cuenta con la dificultad de no tener la absoluta certeza de si las inscripciones fueron incorporadas en el momento de edificación de las fachadas o bien constituyen un añadido posterior -lo que podría ser el caso del primero de los ejemplos analizados en el presente artículo-; pero sí podemos asegurar que tales epígrafes operan en todos los casos, de manera intencionada, una transformación semántica del elemento heráldico. Como ya hemos dicho, mediante esa acción se «personalizan» de alguna manera las armas tradicionales familiares, se transforman en una suerte de divisas con un nuevo sentido matizado o totalmente transmutado. Suponen, por tanto, un elocuente testimonio del deseo de poner de manifiesto, a través de signos externos como puedan ser estos escudos parlantes expuestos al público, no solo honrosas alusiones a la historia y hechos de las familias que los ostentan, sino también determinado deseo o propósito de carácter más específico. Creemos que los escudos «emblematizados» de las casas-palacio de Ios Espadero-Pizarro y Mayoralgo constituyen un ilustrativo ejemplo de esta tendencia, interesante por acercarnos a uno de los mecanismos visuales de afirmación y auto-proclamación públicas, aún no suficientemente conocidos, en los albores de los tiempos modernos. 


\section{Notas}

1 El presente trabajo se ha realizado en el marco del proyecto Biblioteca Digital Siglo de Oro 5 (BIDISO 5), con referencia: FFI2015-65779-P, dirigido por la profesora Nieves Pena Sueiro y financiado por el Ministerio de Economía y Competitividad del Gobierno de España y el Fondo Europeo de Desarrollo Regional (FEDER) desde el 1-01-2016 hasta el 31-12-2019. De igual modo, su realización y presentación se ha llevado a cabo dentro de una Ayuda PRI de la Junta de Extremadura y fondos FEDER una manera de hacer Europa. GR 18072 (Decreto 279/2014), a través del Grupo de Investigación «Patrimonio\&ARTE. Unidad de Conservación del Patrimonio Artístico", dirigido por la Dra. Pilar Mogollón Cano-Cortés.

2 De acuerdo con el más reciente inventario llevado a cabo por el Ayuntamiento de Cáceres, el patrimonio heráldico de su conjunto monumental alcanza los 1268 blasones históricos. En: <http://www.extremadura.com/noticias/2016/01/23/elena-nevado-caceres-cuenta-con-un-patrimonio-heraldico-de-mas-de-1200-escudos> (fecha de consulta: 14-03-2019).

3 Así sucede, por ejemplo, en el blasón de los Ulloa que se conserva en el patio de la Casa de las Veletas, actual sede de las secciones de Arqueología y Etnografía del Museo de Cáceres, con inscripción alusiva a las reformas efectuadas por Alonso de Ulloa en 1476 (Floriano, 1950: 101).

4 «No tenemos aquí ciudad permanente, sino que andamos buscando la del futuro»; la sentencia procede de Hb 13, 14: Non enim habemus hic manentem civitatem, sed futuram inquirimus de acuerdo con el texto de la Vulgata.

5 «En eterna memoria de los justos»; la sentencia parece proceder de Sal 111, 7: In memoria aeterna erit justus; ab auditione mala non timebit ["en memoria eterna permanece el justo; no tiene que temer noticias malas"] de acuerdo con el texto de la Vulgata.

6 «Las cosas moderadas duran» y "Ennoblece el ánimo, y no los hechos de los parientes». El primer lema, MODERATA DURANT, procede de una cita de la obra de Séneca Las Troyanas, II, 259, y fue utilizado por Juan de Horozco como mote de uno de sus Emblemas morales (1604: II, 40), en cuya pictura aparecen las personificaciones de la Medida y el Tiempo para significar con su unión que las cosas realizadas con moderación duran para siempre. En cuanto al segundo, en la orla del blasón que Felipe II concedió al capitán Pedro de León, de Santiago de Chile, que estuvo en Perú al servicio de Francisco Pizarro, se incluía la sentencia latina Nobilitat animos virtus non acta parentum (SOCIEDAD DE BIBLIÓFILOS ESPAÑOLES, 1892: 215-216). En el escudo esgrafiado del patio del mismo palacio de la Isla podemos leer también la celebérrima frase procedente del Eclesiastés 1, 2: VANITAS VANITATUM ET OMNIA VANITAS [«ivanidad de vanidades, todo vanidad!»].

7 Sobre las posibles interpretaciones de estas figuras, véase Sánchez, 1981.

8 Encontramos una breve descripción de las intervenciones realizadas en Miguel Beltrán Lloris (1982: 17).

9 "De gules, dos espadas de plata encabadas de oro cruzadas en aspa con las puntas hacia abajo» (Cordero, 1990: 56).

10 «De oro, cinco ceñidores (ignoramos el color)»; añade Cordero Alvarado (1990: 29 y 60) que la identificación de este cuartel con el blasón de la familia De los Nidos, y no con los Ribera, como se venía haciendo anteriormente, responde al hecho de que aquí presenta cuatro fajas, y los Ribera nunca ostentan más de tres.

11 «De sinople, banda de oro engolada en dragantes de plata; bordura de lata con el lema: AVE MARIA GRATIA PLENA, en letras de sable» (Cordero, 1990: 55).

12 «De oro, un pino de sinople frutado de oro, resaltado de dos osos de sable empinados a su tronco» (Cordero, 1990: 61).

13 En la cartelería instalada por la Junta de Extremadura en la fachada, el inmueble ya aparece identificado como casa-palacio de Cáceres-De los Nidos.

14 Dominus autem mihi astitit, et confortavit me, ut per me praedicatio impleatur, et audiant omnes gentes: et liberatus sum de ore leonis. Liberavit me Dominus ab omni opere malo: et salvum faciet in regnum suum caeleste.

15 Domine, lesu Christe, Rex gloriae, libera animas omnium fidelium defunctorum de poenis inferni et de profundo lacu. Libera eas de ore leonis, ne absorbeat eas tartarus, ne cadant in obscurum. Sed signifer sanctus Michael repraesentet eas in lucem sanctam, quam olim Abrahae promisisti et semini ejus.

16 Quoniam circumdederunt me canes multi; concilium malignantium obsedit me. Foderunt manus meas et pedes meos, [...] Tu autem, Domine, ne elongaveris auxilium tuum a me; ad defensionem meam conspice. Erue a framea, Deus, animam meam, et de manu canis unicam meam. Salva me ex ore leonis, et a cornibus unicornium humilitatem meam.

17 Haec dicit Dominus: Quomodo si eruat pastor de ore leonis duo crura, aut extremum auriculae, sic eruentur filii Israel, qui habitant in Samaria in plaga lectuli, et in Damasci grabato.

18 En el arte funerario romano el león era símbolo del voraz poder de la muerte, y tal dimensión funeraria se perpetuará en la hagiografía cristiana temprana: en ocasiones se habla de leones excavando en el desierto una fosa destinada a sepultura de algunos santos como Antonio Abad, Pablo el Ermitaño, Honofrio o María Egipcíaca.

19 Tomás de Cantimpré, a partir fundamentalmente de noticias de Julio Solino, escribe: «Por otro lado, aunque el león es temible para cualquier animal, sin embargo el aguijón del escorpión le pone nervioso, de manera que cuando lo ve, escapa huyendo como si de un enemigo mortal se tratara. [...] Así pues el león capturado por los cazadores se aterroriza ante los dardos; teme también el estrépito de las ruedas y, sobre todo, al fuego; según Jacobo, también le asusta un gallo blanco» (De natura rerum IV,54; Tomás de Cantimpré, 1974: 42).

20 Por todo ello se comprende el sentido de la bendición de Jacob, que ve un león en su hijo Judá (Gn 49, 9), así como en la bendición de Dan por parte de Moisés, donde se hace la misma referencia al cachorro del felino (Dt 33, 22).

21 En pasajes como Os 5, 14; 13, 8; o 11, 8-11, el Señor adopta figuradamente la forma del terrible animal que desgarra, despedaza o arrebata; en otros textos proféticos (Am 1, 2; 3, 8; Os 11, 9-10), la voz de Dios se compara el rugido de un león como anuncio de grandes estragos. Ezequías ve en su enfermedad un ataque que viene de Dios bajo la forma de aquella bestia (Is 38, 12-13).

22 Esta imagen de Sansón es, en efecto, modelo tipológico del Salvador en el Antiguo Testamento, lo que justifica que frecuentemente se represente a Cristo como vencedor de personificaciones animales de índole maléfica como el león, el dragón o el basilisco.

23 Como en Sal 91, 13 y en otros pasajes de este libro ya indicados más arriba. En esta última cita se inspiran algunas obras artísticas medievales, como es el caso de una de las placas del díptico de marfil de Genoels-Elderen (Bélgica, pieza carolingia de inicios del s. IX), donde Cristo, dispuesto en pie, pisa a un león junto a las demás criaturas diabólicas citadas en este pasaje: una víbora, un dragón y un basilisco. Un pequeño león, emparejado con un basilisco, vuelve a aparecer a los pies del conocido como Beau Dieu, o Cristo Salvador bendiciente del parteluz de la portada occidental central de la catedral de Amiens (ca. 1220-35), en Francia.

24 La mayor parte de las referencias bíblicas reunidas en los párrafos precedentes proceden de Manfred Lurker (1994: 129, s. v. «León») y Maurice De Cocagnac (1994: 196-199). 
25 Maarten De Vos llevó a cabo una versión de La tentación de san Antonio (ca. 1591-94, Amberes, Koninklijk Museum voor Schone Kunsten) en la que dos leones se disponen al frente del tropel de seres grotescos que se enfrentan al santo abad en la mitad inferior de la composición. De nuevo en otra versión de este tema - La tentación de san Antonio Abad- de Annibale Carracci (1597, Londres, National Gallery) un temible león, esta vez cornudo, amenaza al indefenso eremita. Francisco de Zurbarán representó a un fiero león en su Combate/Lucha de fray Diego de Orgaz contra los demonios en la sacristía del monasterio de Nuestra Señora de Guadalupe (Cáceres, 1639), acompañando al felino de una figura antropomorfa que realiza gestos vulgares dirigidos al fraile mientras este trata de alejar a ambos con un palo. Según el relato tradicional recogido por los diversos cronistas, fray Diego ahuyentó a los tres demonios que acudieron a tentarle a su celda -bajo la apariencia, respectivamente, de león, oso y mujer hermosa-, no tanto con el palo con el que se enfrentó a ellos inicialmente, sino a través de la oración, invocando el nombre de Jesús y la Virgen María en su auxilio.

26 Según este mismo autor, Cesare Ripa se inspira en precedentes medievales para considerar a la Complexión o Carácter colérico como un joven delgado, de tez amarillenta y fiera mirada, sosteniendo una espada, y acompañado de un escudo con llamas representadas en él, y un león, por ser el colérico muy semejante al félido iracundo. Así lo representa también Andrea Alciato en sus Emblemata (1621: emblema 63 «Ira», p. 285).

27 También para Horapolo este animal será jeroglífico de «Coraje», «Fuerza física» o «Vigilancia».

28 El lema es Sic pascua divitum pauperes, «Así los pobres son pasto de los ricos». Imagen y mote se sustentan directamente en pasajes bíblicos como «Venatio leonis onager in eremo: sic et pascua divitum sunt pauperes» [Caza de leones son los onagros en el desierto, así los pobres son presa de los ricos] (Si 13, 19 [23 en la Vulgata]); o "Leo rugiens et ursus esuriens, princeps impius super populum pauperem» [León rugiente, oso hambriento, / es el malo que domina al pueblo débil] $(\operatorname{Pr} 28,15)$.

29 Según De Mayoralgo y Lodo (2004: 115), Blasco Muñoz, el segundo de este nombre, ya poseía el núcleo primitivo del edificio a inicios del s. XIV.

30 En las reformas de 2003 se dejaron al descubierto los arcos del lado norte del patio, de modo que ahora se pueden contemplar dos alas abiertas en galería. En este espacio se conservan varios escudos de armas que recuerdan varias alianzas matrimoniales del linaje Mayoralgo (De Mayoralgo y Lodo, 2004: 120).

31 Además de las estancias cubiertas, el edificio cuenta con un jardín abierto en la parte posterior que limita con el adarve. Desde él se pasaba a través de un arco elevado sobre esta vía, construido en el s. XVIII, a la Torre de los Púlpitos, en la muralla de la ciudad, desde la que se divisa una excelente panorámica de la Plaza Mayor.

32 Como indica José Miguel de Mayoralgo (2004: 113), resultan frecuentes en Cáceres los casos en los que, tras la ampliación y adquisición de casas colindantes, habiendo alcanzado a ocupar la mansión una extensión considerable, y siempre y cuando sus nobles propietarios hayan mantenido su alta posición social y económica, estos procedan a reconstruir sobre todo las fachadas principales de acuerdo con las corrientes arquitectónicas imperantes en el momento. De ese modo, en la adaptación del palacio de Mayoralgo al nuevo carácter residencial, fueron desapareciendo o integrándose en su nueva estructura las dos torres -y el principio de una tercera- con que, de acuerdo con las fuentes, llegó a contar el edificio medieval (De Mayoralgo, 2004: 116). Hay documentación que indica que en el año 1537, según Rubio Rojas (1978: 70), se sigue trabajando en la fachada de la casa.

33 Este blasón de los Mayoralgo es una verdadera rareza en la armería española en lo que se refiere a la presentación de sus armas en «partido dimidiado»; también en el conjunto de Cáceres se localiza el del linaje de los Moragas, con esta misma forma de partición (Cordero, 1989: 23). Floriano Cumbreño (1950: 63) señala que el blasón principal de la fachada es de «piedra granítica fina y de tonalidad dorada, procedente de las canteras de Salamanca o Ávila».

34 Añade Cordero Alvarado que el diseño de los lambrequines, como se aprecia en ciertas composiciones de la escalera de la Universidad de Salamanca, parece extraído de repertorios humanísticos; advierte además que una decoración muy similar es la dispuesta por Pedro de Marquina en 1563 flanqueando el blasón del balcón esquinado del palacio de Godoy, también en Cáceres.

35 Es parte de la oración de un exiliado que habita lejos de la tierra de Yahveh, y aspira regresar a la ciudad santa para permanecer al amparo de su Dios y la sombra de su tabernáculo. En los salmos es frecuente llamar a Dios la Roca de salvación, en cuanto que a su amparo el fiel es inaccesible a los ataques de sus enemigos. Con ese símil el poeta destaca el carácter protector de Yahveh: es la torre fortificada desde la que se puede hace frente al enemigo. Este pasaje se ha puesto en relación con Sal 31, 3-4: Esto mihi in Deum protectorem, et in domum refugii, ut salvum me facias: quoniam fortitudo mea et refugium meum es tu; et propter nomen tuum deduces me et enutries me [«Sé para mí una roca de refugio, / alcázar fuerte que me salve; / pues mi roca eres tú, mi fortaleza, / y, por tu nombre, me guías y diriges»], y con Sal 46, 2: Deus noster refugium et virtus [«Dios es para nosotros refugio y fortaleza»]

36 Parte de la información que desarrollamos a continuación procede de García, 2010: 148-154.

37 Aristóteles añade que este rasgo del águila se debe a un castigo que recibió cuando el ave era un ser humano, al comportarse de manera inadecuada con un peregrino. Cfr. Antígono de Caristo, Hist. mir., 52.

38 También el comediógrafo Publio Terencio Afro -Heautontimorumenos 521-, y Ausonio -Commemoratio professorum Burdigalensium 5, 22- hacen referencia a la vejez del ave.

39 Este texto sigue muy de cerca a la versión griega más primitiva, excepto en la alegorización doctrinal: en tanto la latina considera el comportamiento del águila una imagen del Bautismo, la traducción griega entiende que representa con más propiedad el sacramento de la Confesión. Cfr. el texto latino con el griego que ofrece I. Malaxecheverría (1986: 73). Pseudo-Estacio de Antioquía-Comm. in Hex., col. 731-reproduce, en su comentario sobre el águila, el pasaje inicial del Fisiólogo griego, aunque desecha toda la alegorización posterior.

40 «Tú, pues, hombre espiritual, cuando te veas bajo el peso de la multitud de los pecados, sube a lo alto -esto es, a la propia conciencia de ti mismo-y arrójate contra la piedra -es decir, la ortodoxia de la fe-; llora la multitud de tus pecados y, tras lavarte en las aguas perpetuas -es decir, las lágrimas-, caliéntate con los rayos del Sol -esto es, acércate al calor de la penitencia en la comunidad de los fieles y en el Santo Espíritu-; arroja las legañas -esto es, los pecados-; enseguida se renovará tu juventud, como la del águila, y serás llamado justo en presencia de Dios».

41 En relación con el símil piedra-Cristo vid. la Primera epístola a los Corintios 10, 4: «[...] y todos bebieron la misma bebida espiritual, pues bebían de la roca espiritual que les seguía; y la roca era Cristo». Hugo de Folieto (Aviarium, 60) retoma esta idea en el s. XII: "La roca es Cristo, el águila cualquier hombre justo que afila su pico en la roca, mientras, mediante las buenas acciones, regresa gustoso junto a Cristo».

42 «El águila toma su nombre de la agudeza de su vista (acumen oculorum). Se dice que es esta tan penetrante, que cuando se mantiene inmóvil sobre los mares sostenida por sus alas a una altura tal que no es visible al ojo humano, ella desde tan elevada altura ve nadar a los pececillos, sobre los que se precipita a manera de un rayo y, haciendo presa en ellos, vuela hacia la costa».

43 Para otros recopiladores de símbolos y jeroglíficos del siglo XVII la renovación del águila será imagen de los hombres que abandonan las «plumas del pecado» mediante la penitencia, y reviven en Cristo. Así sucede en los tratados de Archibald Simson (1622: 27), Jakob Masen (1664: cap. LXXIII, p. 858) o Francisco Marcuello. Este último (1617: cap. I, fol. 14 v) alegoriza: «Primeramente ha de volar (el águila) a lo alto, por la consideración de las cosas eternas, y por el trabajo de la 
penitencia: y encenderse con el Sol del amor divino, y con el deseo de las cosas celestiales: y bajar por humildad a la agua de la compunción y devoción: y dejar las plumas de la conversación mundana: y así podrá volver al estado de gracia, y de las virtudes perdidas por el pecado: y renovar en sí la juventud de las buenas costumbres, mediante la penitencia [...]”. También para Filipo Picinelli este tópico constituye una excelente alegoría del Bautismo (1680: lib. IV, cap. 7, 78, p. 149). En cuanto a Andrés Ferrer de Valdecebro (1683: lib. I, cap. 9, pp. 40-42), entiende que todo este proceso de renovación es jeroglífico de la Juventud.

44 Ad Phys. 6, p. 22.

45 También los tratadistas simbólicos del siglo XVII mantendrán el mismo significado -la liberación de los vicios mediante la penitencia para lograr la vida eternaconforme a la tradición patrística. Así sucede en los textos de Archibald Simson (1622: 26) o Jakob Masen (1664: cap. LXXIII, p. 858).

46 Existe una honrosa excepción: el detenido y documentado análisis que la profesora Mogollón Cano-Cortés ha aportado recientemente a propósito de los elementos icónicos y epigráficos de la espléndida fachada principal del palacio de los Golfines de Abajo (2017: 376-389).

\section{Bibliografía}

ALCIATO, Andrea (1621), Emblemata, Petrum Paulum Tozzium, Patavii.

AGUSTÍN DE HIPONA (1964), «Sermones», en Obras de San Agustín. VII: Sermones, prólogo y traducción castellana de Amador del Fueyo, Biblioteca de Autores Cristianos, Madrid.

- (1964-1966), «Enarraciones sobre los Salmos», en Obras de San Agustín, vols. XIX-XXI, traducción castellana de Balbino Martín Pérez, Biblioteca de Autores Cristianos, Madrid.

ÁlVAREZ ROJAS, Antonio y GARRIDO SANTIAGO, Manuel (1984), Museo de Cáceres. Sección Bellas Artes. "Casa del Mono», catálogo-guía, Cáceres.

ANDRÉS ORDAX, Salvador (dir.) y PIZARRO GÓMEZ, Francisco Javier (coord.) (2006), Monumentos artísticos de Extremadura, Editora Regional de Extremadura, Badajoz, 2 vols.

ARISTÓTELES DE ESTAGIRA (1990), Historia de los animales, introducción, traducción castellana y notas de José Vara Donado, Akal, Madrid. BELTRÁN LLORIS, Miguel (1982), Museo de Cáceres. Sección de Arqueología, Ministerio de Cultura, Dirección General de Bellas Artes, Archivos y Museos, Madrid.

BORJA, Juan de (1581), Empresas morales, Jorge Nigrín, Praga.

BUENO FLORES, Antonio (1990), Cáceres. Conjunto monumental, Editorial García-Plata, Madrid.

CALLEJO SERRANO, Carlos (1980), Cáceres monumental, Plus Ultra, Madrid.

CAMERARIUS, Joachim (1654), Symbolorum et emblematum ex volatilibus et insectis desumptorum centuria tertia, Joh. Ammonii, Frankfurt. CORDERO ALVARADO, Pedro (1989), Guía heráldica de Cáceres, Editorial García-Plata, Cáceres.

- (1991), Cáceres en sus escudos y monumentos, Editorial García-Plata, Cáceres.

DE COCAGNAC, Maurice (1994), Los símbolos bíblicos. Léxico teológico, Desclée de Brouwer, Bilbao.

DE COVARRUBIAS HOROZCO, Sebastián (1610), Emblemas morales, Luis Sánchez, Madrid.

DE MAYORALGO Y LODO, José Miguel (2004), «El palacio de Mayoralgo. Historia de una casa noble cacereña», en W. AA., El palacio de Mayoralgo. Sede institucional de la Caja de Extremadura, Caja de Extremadura, Cáceres.

EPIFANIO DE SALAMIS (atrib.) (1587), Sancti patris nostri Epiphanii episcopi Constantiae Cypri ad Physiologum. Eiusdem in die desto palmarum sermo. D. Consali Ponce de Leon hispalensis [...] apud Zannettum et Russinellum, Romae (otra edición en Antuerpiae, Officina Christophori Plantini, 1588).

- (atrib.) (1986), El Fisiólogo atribuido a san Epifanio, traducción castellana de Francisco Tejada Vizuete con introducción y comentarios de Santiago Sebastián López, Tuero, Madrid.

FERRER DE VALDECEBRO, Andrés (1683), Govierno general, moral, y politico. Hallado en las aves más generosas, y nobles. Sacado de sus naturales virtudes, y propiedades, Bernardo de Villa-Diego, Madrid.

FLORIANO CUMBREÑO, Antonio C. (1950), Repertorio heráldico de Cáceres. Escudos nacionales y locales de las familias primates, Institución de Servicios Culturales, Diputación Provincial de Badajoz, Badajoz (separata de la Revista de Estudios Extremeños, vol. Vl: I-II, 1950, pp. 3-105).

GARCÍA ARRANZ, José Julio (2010), Symbola et emblemata avium. Las aves en los libros de emblemas y empresas europeos de los siglos XVI y XVII, SIELAE/Sociedad de Cultura Valle Inclán, La Coruña. 
GEORGE, Wilma y YAPP, Brunsdon (1991), The Naming of the Beasts. Natural History in the Medieval Bestiary, Gerald Duckworth and Co. Ltd., Londres.

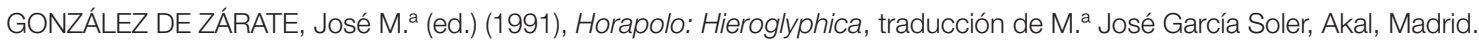

GREGORIO MAGNO (1998), Libros morales/1 (libros I-V), traducción de José Rico Pavés, Ciudad Nueva, Madrid.

GUGLIELMI, Nilda y AYERRA, Manuel (eds.) (1971), El Fisiólogo, bestiario medieval, Editorial Universitaria, Buenos Aires. HORAPOLO DEL NILO (1543), Hieroglyphica, Johannes Kerver, París.

HOROZCO Y COVARRUBIAS, Juan de (1604), Emblemas morales de Don Juan de Horozco y Covarruvias, Alonso Rodríguez, Zaragoza.

LODO MAYORALGO, J. M. (1971), Viejos linajes de Cáceres, Editorial Extremadura, Cáceres.

LOZANO BARTOLOZZI, M. ${ }^{a}$ del Mar (1980), El desarrollo urbanístico de Cáceres siglos XVI-XIX, Servicio de Publicaciones de la Universidad de Extremadura, Cáceres.

LURKER, Manfred (1994), Diccionario de imágenes y símbolos de la Biblia, trad. castellana de Rufino Godoy, Ediciones El Almendro, Córdoba. MÉLIDA ALINARI, José Ramón (1924), Catálogo Monumental de España. Provincia de Cáceres (1914-1916), Ministerio de Instrucción Pública y Bellas Artes, Madrid.

MALAXECHEVERRÍA, Ignacio (ed.) (1986), Bestiario medieval, Siruela, Madrid.

MARCUELLO, Francisco (1617), Primera parte de la Historia Natural, y Moral de las aves, Juan de Lanaja y Quartonet, Zaragoza. MARIÑO FERRO, Xosé Ramón (1996), El simbolismo animal. Creencias y significados en la cultura occidental, Encuentro, Madrid.

MASEN, Jakob (1664), Speculum imaginum veritatis occultae, exhibens Symbola, Emblemata, Hieroglyphica, Aenigmata, omni, tam materiae, quam formae varietate, exemplis simul, ac praeceptis illustratum, Ionnis Antonii Kinchii, Coloniae Ubiorum.

MOGOLLÓN CANO-CORTÉS, Pilar (1995a), «Palacio de los Mayoralgo», en FERNÁNDEZ LÓPEZ, José y PIZARRO GÓMEZ, Francisco Javier (coords.), Extremadura. Cáceres y Badajoz, col. «La España Gótica», Ediciones Encuentro-Editora Regional de Extremadura, Madrid, pp. 117-119.

- (1995b), “Casa de los Espadero-Pizarro», en FERNÁNDEZ LÓPEZ, José y PIZARRO GÓMEZ, Francisco Javier, Extremadura. Cáceres y Badajoz, col. «La España Gótica», Madrid, Ediciones Encuentro-Editora Regional de Extremadura, pp. 119-122.

- (2017), «Símbolos e imágenes de la fachada de la casa del camarero Sancho de Paredes en Cáceres», Hispanic Research Journal, n. ${ }^{\circ}$ 18:5, pp. 373-390.

PICINELLI, Filippo (1680), Mondo simbolico formato d'imprese scelte, spiegate, et illustrate con sentenze, ed eruditioni Sacre, e Profane, Francesco Vigone, Milán.

PIZARRO GÓMEZ, Francisco Javier (2002), Cáceres. Paisajes urbanos de Extemadura, Cicón, Cáceres.

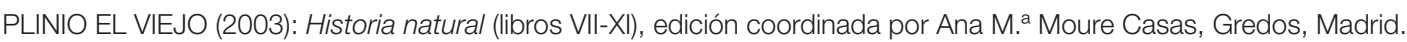

RIPA, Cesare (1987), Iconología, traducción castellana de Juan y Yago Barja, Akal, Madrid, 2 vols.

REUSNER, Nicolas (1581), Emblemata Nicolai Reusneri lc. partim ethica, et physica: partim verò historica, et hieroglyphica, leremiae Reusneri Leorini, Francoforti.

RUBIO ROJAS, Antonio (1978), Cáceres. Ciudad histórico-artística, Madrid.

SÁNCHEZ RODRíGUEZ, Mariano (1981), “Un relieve de la 'Casa del Mono': claves para una interpretación socio-histórica», en Actas del VI Congreso de Estudios Extremeños, 1979, Cáceres.

SEBASTIÁN LÓPEZ, Santiago (ed.) (1986), El Fisiólogo atribuido a san Epifanio, trad. castellana de Francisco Tejada Vizuete, Tuero, Madrid. SIMSON, Archibald (1622), Hieroglyphica animalium terrestrium, volatilium, natatilium, reptilium, insectorum, vegetivorum, metallorum, lapidum: etc. Quae in scripturis Sacris inveniuntur, Thomas Finlason, Edimburgo.

SOCIEDAD DE BIBLIÓFILOS ESPAÑOLES (1892), Nobiliario de conquistadores españoles, Imprenta de M. Tello, Madrid.

TERVARENT, Guy de (1985), Atributos y símbolos en el arte profano. Diccionario de un lenguaje perdido, Ediciones del Serbal (2002), Barcelona.

TOMÁS DE CANTIMPRÉ (1974), Thomas Cantimpratensis: De natura rerum iv-vii, edición y traducción de Francisco José Talavera Esteso, el editor, Málaga.

VALERIANO BOLZANI, Pierio (1567), Hieroglyhica, sive de sacris aegytiorum, aliarumque gentium literis commentarii, Thomam Guarinum, Basilea. 